\title{
The Development of the Forebrain in Trichosurus Vulpecula
}

\author{
By \\ Francis James WARNER \\ Department of Anatomy, University College, London, England and Department \\ of Clinical Research Eastern Pennsylvania Psychiatric \\ Institute, Philadelphia, Pennsylvania \\ -Received for Publication, April 18, 1980-
}

Key Words: Brain, Australian marsupial.

Summary. 1) In the early stages of the Trichosurus vulpecula embryos, there could be noted the D1, D2, and D3 pallial zones, and the basal zones B1, B2, B3, and B4. These pallial and basal telencephalic zones resemble those noted by Kuhlenbeck (1938) in the Tropidonatus natrix embryo; and also that in the chick embryo of 5 days and 16 hours.

2) At the $16 \mathrm{~mm}$ Perameles nasuta embryo and the $19 \mathrm{~mm}$ stage of Trichosurus vulpecula, the D2 pallial zone splits into three areas, namely the D2 am area, the D2 al area and the $D(2+1) c$ pallial area. The $D 2$ am zone becomes the parahippocampal cortex; the $\mathrm{D} 2$ al zone becomes the neocortex, and the $\mathrm{D}(2+1) \mathrm{c}$ zone becomes the pyriform cortex. The D3 pallial zone in Trichosurus vulpecula gives rise to the hippocampus.

3) In Trichosurus vulpecula the lateral part of the nucleus epibasalis anterior or epistriatum becomes the claustrum. The claustrum is derived from the zone D1 and the basal zones $B 1$ and $B 2$. A doubling of the claustrum could be definitely noted at the 44 and $48 \mathrm{~mm}$ stages of Trichosurus vulpecula.

4) In Trichosurus vulpecula the medial part of the epistriatum or nucleus epibasalis anterior gives rise to the caudate nucleus and the putamen. They are both derived from the zones D1, B1, and B2. The nucleus epibasalis anterior is equivalent to the neostriatum of Kappers (1921).

5) At the $30 \mathrm{~mm}$ stage of Trichosurus vulpecula, the primordium of the globus pallidus could be noted. It is derived from an area of the dorsolateral part of the hypothalamic zone. The globus pallidus in mammals is a differentiation of the anterior entopeduncular nucleus. The anlage of the globus pallidus migrates rostrally; and at the $40 \mathrm{~mm}$ stage, it joins the putamen to become the mammalian form the globus pallidus.

6) The periamygdalar cortex, which becomes the amygdalar nucleus $A$; is derived from the basal zones B1, B2, and B3. The other amygdalar nuclei, namely the Gamma, Delta, and the Beta amygdalar nuclei are derived from the caudal parts of the fused zones $\mathrm{D} 1+\mathrm{B} 1+\mathrm{B} 2$. The amygdala is derived from the posterior part of the nucleus epibasalis.

7) The precommissural hippocampus could be first noted, at the precommissural telencephalic level at the $41 \mathrm{~mm}$ stage of Trichosurus vulpecula. It is well defined at the 44 and $48 \mathrm{~mm}$ stages.

8) In the $30 \mathrm{~mm}$ Trichosurus vulpecula embryo, the primordium of the cornu Ammonis could be noted, at the caudal telencephalic level. At the 44 and $48 \mathrm{~mm}$ Tri- 

chosurus vulpecula embryos the cornu Ammonis and dentate fascia began to resemble
that form noted in the adult state.

\section{Introduction}

Gronberg (1901) described the development of the forebrain in the primitive insectivore, the Euroropean hedgehog, (Erinaceous Europeus). Hines (1922) has described the development of the forebain in the human form, in considerable detail. Hines (1923) has also described the development of the forebrain in Sphenodonpunctatum. Kuhlenbeck (1922, 1924, 1925, 1929 and 1938) has discussed the development of the zonal system of the forebrain in the ichtyopsida, reptiles, birds, marsupials, and primitive mammals, namely the mole as well as that of the pig.

Kuhlenbeck (1938) described the development of the forebrain of the chick in considerable detail. Warner (1946) described the development of the forebrain in the American water snake. Tilney and Kubie (1931) described the development of forebrain in the cat in great detail. Tilney (1932-1934) has described the development of the forebrain in the albino rat. Tilney (1938) has described the development of the forebrain and particularly that of the hippocampus in the American opossum. Because in the past, there have been few systematic studies made of the development of the forebrain in the Australian marsupials, it was deemed advisable to make a systematic study of the development of the forebrain in certain of the Australian marsupials, namely Trichosurus vulpecula and a distantly related form Perameles nasuta.

\section{Materials and Methods}

Twenty-five series of Trichosurus vulpecula embryos and two series of
Perameles nasuta embryos were available for this work. The two series of Perameles nasuta embryos which were used in this work were from a marsupial distantly related to Trichosurus vulpecula. These marsupial embryos were embedded in paraffin and were sectioned in the transverse plane. All of these series of embryos were stained with the hematoxylin and eosin stain. Inasmuch as suitable Trichosurus vulpecula embryos of certain crucial stages were not available for study, the $16 \mathrm{~mm}$ and the $23 \mathrm{~mm}$ stages of the Perameles nasuta form were used to illustrate these stages. However, this work dealt mainly with the development of the forebrain in the Trichosurus vulpecula species.

\section{Description}

Trichosurus vulpecula, $7.25 \mathrm{~mm}$

The telencephalic vesicle at this stage shows the characteristic vertebrate pattern of longitudinal telencephalic zones, noted by Kuhlenbeck (1924, 1925, 1929 and 1938) in the chick and other forms. Thus, the pallial telencephalic wall zones, namely D1, D2, and D3 zones could be noted (Fig. 1, D1, D2 and D3). The basal telencephalic zones, namely the B1, B2, and B3 zones could also be demarcated (Fig. 1, B1, B2 and B3). Dorsally in the midline region of the roof plate, the developing paraphysis could be observed (Fg. 1, pa.). It consisted of a small evagination of the telencephalic roof plate. The wall of the telencephalon consisted of an inner ependymal layer, fairly well defined mantle cell layer and a poorly demarcated thin outer marginal layer. 
Trichosurus vulpecula, $8.5 \mathrm{~mm}$

In the $8.5 \mathrm{~mm}$ Trichosurus vulpecula embryo the telencephalon was more fully evaginated. In the pallial part of the telencephalic vesicle the zones D1, $\mathrm{D} 2$, and D3 were readily demarcated (Fig. 2, D1, D2 and D3). There could be noted some thickening of the telencephalic wall, particularly in the zones $\mathrm{D} 1$ and $\mathrm{B} 1+\mathrm{B} 2$. The zones $\mathrm{B} 1$ and $\mathrm{B} 2$ were fused at this stage (Fig. 2, $\mathrm{B} 1+\mathrm{B} 2$ ). The telencephalic wall consisted of an inner ependymal layer anda quite well defined mantle cell layer. There could also be noted a thin marginal layer, which was more distinct that at the previously described stage.

At the ventrolateral border of the telencephalic vesicle a sulcus could be seen, which was the sulcus telencephalodiencephalicus (Fg. 2, std.). This sulcus separates the telencephalon from the diencephalon. Ventral to this sulcus the rostral extremity of the hypothalamic diencephalic zone could be observed (Fig. 2, hy.). Dorsomedially there was noted an area of telencephalic evagination, which forms part of a ridge forming the di-telencephalic boumdary. This structure forms tho velum transverum (Fg. 2, v.t.).

\section{Trichosurus vulpecula, $10 \mathrm{~mm}$}

In the $10 \mathrm{~mm}$ stage the pallial telencephalic zones D1, D2, and D3 were quite well defined, and the telencephalon was more evaginated than at the stage previously studied (Fg. 3, D1, D2 and D3). Just medial to the pallial D3 zone the thin roof plate could be seen (Fg. 3, tel. rf. pl.). At the ventrolateral part of the outer margin of the forebrain wall, there could be noted the sulcus telencephalodiencephalicus (Fg. 3, std.). At the inner margin of the forebrain wall, at the telencephalo-diencephalic border zone, a ring shaped swelling of the forebrain wall could be observed. This thickened area forms the torus hemisphaericus of the forebrain wall; which is coincident with the external telo-diencephalic sulcus. It likewise delimits the telencephalon from the diencephalon (Fig. 3, t.h.). Ventral to this sulcus the rostral extremity of the hypothalamic diencephalic zone was observed (Fig. 3, hy.). In the hypothalamic zone the sulcus lateralis infundibuli was noted at its medial border (Fig. 3, s. i. a.). At the ventromedial part of the hypothalamic zone a pouch could be seen, which represents the beginning of the infundibulum (Fig. 3, inf.). The telencephalic wall was thicker than at the previous stage studied. It consisted of an inner ependymal layer and a mantle layer, which was better defined, and an outer marginal zone which was slightly better defined than at the previously studied stage (Fig. 3, 1 and 2).

Trichosurus vulpecula, $11.5 \mathrm{~mm}$

In the $11.5 \mathrm{~mm}$ Trichosurus vulpecula embryo there could be noted a thickening of the telencephalic wall, particularly in the pallial zone D1 and the basal zones B1 and B2. The pallial telencephalic zones, namely the zones D1, D2, and D3 were well defined (Fig. 4, D1, D2 and D3). The basal zones B1, B2, B3 and B4 were likewise clearly defined (Fig. 4, B1 B2, B3 and B4). A sulcus could be noted on the ventricular wall, which was the sulcus fd2. This sulcus indicates the boundaries of the telencephalic pallial zones D1 and D2 (Fig. 4, fd. 2).

In the telencephalic wall the ependymal and mantle cell layers could be readily demarcated (Fig. 4, 1 and 2). The mantle layer particularly in the zones D1 and B1 were thicker than at the previously described stage. The outer marginal layer had likewise become better defined. In the ventral part of the medial telencephalic wall there could be noted a 
ventral part, which was namely the basal zone B3. Lying just dorsal to it, there was seen the basal zone B4, which first differentiates at this stage. The telencephalon of the $11.5 \mathrm{~mm}$ stage resembled that of the embryo of Tropidonotus natrix, as noted by Kuhlenbeck (1938).

Trichosurus vulpecula, $13 \mathrm{~mm}$

In the $13 \mathrm{~mm}$ Trichosurus vulpecula embryo the pallial longitudinal zones D1, D2, and D3 were clearly outlined (Fig. 5, D1, D2 and D3). The pallial zone D1 and the basal zones $\mathrm{B} 1$ and $\mathrm{B} 2$ were slightly thicker than at the previously described stage. The basal zones B3 and B4 of the medial telencephalic wall were more definitely demarcated, particularly the zone B4 (Fg. 5, B1, B2, B3 and B4). The ependymal and mantle layers of the telencephalic wall had become slightly thicker than at the previously described stage; particularly in the pallial zone $\mathrm{D} 1$ and the basal zone $\mathrm{B} 1$ and $\mathrm{B} 2$ (Fg. 5, B1 and B2). The marginal zone was well defined.

In a transverse section of the telencephalon more caudal than that shown in the previously described figure, at the level of the foramen of Munro, the pallial telencephalic wall zones D1, D2 and D3 were well defined (Fg. 6, D1, D2 and D3). At this level the basal telencephalic zone $\mathrm{B} 1$ was fused with the zone B2 (Fg. 6, $B 1$ and B2). In the ventrolateral part of the outer margin of the wall of the telencephalon there was still to be seen the sulcus telencephalo-diencephalicus (Fig. 6, std.).

In the inner margin of the telencephalic wall, at an area coincident with the outer sulcus telencephalo-diencephalicus, a marked thickening of the forebrain wall could be noted. This thickened area forms the torus hemisphaericus (Fig. 6, t. h.). It was considerably thicker than at the $10 \mathrm{~mm}$ stage, particularly in its mantle cell layer. In the basal midline of the torus hemisphaericus there was noted an area of thickening, which forms the torus transversus (Fig. 6, t.t.). According to Kuhlenbeck (1936), the torus transversus becomes the bed of the anterior commissure; and the dorsal part of the torus hemisphaericus remains epithelial and thin; and becomes the velum transversum. At this level the rostral extremity of the dorsal thalamus and the ventral thalamic zone could be observed (Fig. 6, t. d. and t. v.). Ventrally the rostral extremity of the hypothalamic zone could be noted. At the medial border of the hypothalamic zone, the sulcus intraencephalicus anterior could be demarcated (Fg. 6, Si.).

\section{Perameles nasuta, $16 \mathrm{~mm}$}

In the $16 \mathrm{~mm}$ Perameles nasuta embryo there could be seen the remaining part of the D1 pallial zone, which lies just above the B1 zone (Fg. 7, D1). More dorsally the D2 zone had split up and had given rise to three parts; which were namely, the D2 am zone, the D2 al zone, and the $D(2+1)$ c zone. The D2 al zone showed evidence of a considerable degree of thickening of the telencephalic wall (Fg. 7, D2 al, D2 am and D(2+1)c). According to Kuhlenbeck (1926), the primordium neopallii is an early development of the $\mathrm{D} 2$ al zone in reptiles. He also stated that the $\mathrm{D}(2+1) \mathrm{c}$ pallial zone is formed from the lateral part of the zones D2 and D1. Dorsomedially and close to the medial part of telencephalic wall, there could be seen the wall of the D2 am telencephalic zone, which was thinner than in the D2 al zone.

According to Kuhlenbeck (1924 and 1929) the D2 am zone is the matrix from which the future parahippocampal zone is derived. Ventromedial to the zone D2 am there could be noted the zone of D3. This zone which according to Kuhlenbeck 
(1924 and 1929), is the anlage of the future hippocampal formation, showed no special differention as yet. The basal zones B1 and B2 were clearly demarcated, and the telencephalic wall in these zones was considerably thicker than in the previously described stages (Fg. 7, B1 and B2). Ventromedially there could be noted the B3 basal zone, which showed evidence of considerable thickening of the telencephalic wall. Lying just above it, there could be seen the B4 basal zone. The telencephalic wall was quite thin in the B4 basal zone (Fg. 7, B3 and B4).

In a more caudal level of the telencephalon at the level of the foramen of Munro, the pallial telencephalic zones were similar to that seen in the more rostral level of the forebrain. At the ventrolateral border of the telencephalon the sulcus telo-diencephalicus ceuld be seen. The B2 and B3 basal zones were fused at this level (Fg. 8, B2 and B3). In the D2 al pallial zone the marginal layer could be clearly noted (Figs. 7 and 8, M. G.).

\section{Trichosurus vulpecula, $19 \mathrm{~mm}$}

At this stage the pallial D2 zone had split into the well defined D2 am zone, the $\mathrm{D} 2$ al zone, and the $\mathrm{D}(2+1) \mathrm{c}$ pallial zone (Fg. 9, D2 am, D2 al and D $(2+1) \mathrm{c}$ ). Dorsomedial to the D2 al zone there could be noted the D3 pallial zone, which was considerably thicker than at the previously described stage (Fg. 9, D3). The mantle cell layer of this zone had become considerably thicker than at the $16 \mathrm{~mm}$ stage. However there no evidence of any special cortical differentiation as yet in this zone.

The wall of the remaining part of the D1 zone had also become greatly thickened, particularly in its mantle cell layer (Fig. 9, D1). The telencephalic wall of the B1 and B2 basal telencephalic zones had likewise become greatly thickened (Fig.
$9, \mathrm{~B} 1$ and B2). In the ventromedial part of the telencephalic wall the basal B3 zone could be noted (Fig. 9, B3). Lying just dorsal to it there could be seen the basal telencephalic B4 zone (Fig. 9, B4). Just ventrolateral to the $B 1$ telencephalic zone, there could be seen at the peripheral part of the telencephalic wall an area of cell condensation (Fig. 9, Bs. vla.pr.); which forms the primordium of the future tuberculum olfactorium. The tuberculum olfactorium is derived from the zones B2 and B3, according to Kuhlenbeck (1969).

At a more caudal level of the telencephalon, at the level of the foramen of Munro, the pallial D2 am zone could be noted (Fg. 10, D2 am). The telencephalic wall in this zone consisted of an ependymal layer, a mantle layer, and a marginal layer. Ventrolaterally the D2 al zone could be observed. In this zone the telencephalic wall consisted of an ependymal layer, a mantle layer, and a well defined marginal layer. The remaining part of the D1 pallial zone had become greatly thickened and protruded into the lateral ventricle (Fig. 10, D1). The basal telencephalic B1 zone had also become greatly thickened, and it likewise protruded into the lateral ventricle (Fig. 10, B1). The sulcus telo-diencephalicus could be noted at the ventral border of this level of the forebrain (Fig. 10, std.). The preoptic recess was seen in the ventral midline area of the telencephalon (Fig. 10, r. p. o.).

At the ventrolateral extremity of the telencephlic wall there could be noted an area of cells, which forms an area of transition between the tuberculum olfactorium and the periamygdalar cortex (Fig. 10 , ar. trns. vls. pr.). Lying lateral to the telencephalic zones, namely, the remaining part of the zone D1 and the pallial D2 zone, at the periphery of the telencephalic wall; there could be noted a thin band 
like area of cell condensation. This area forms the pallial zone D2+1c; which according to Kuhlenbeck (1929), gives rise later to the pyriform cortex (Fig. $10, D(2+1) c)$. Dorsomedially there could be noted the D3 pallial zone. As at the more rostral level of the telencephalon there was as yet no evidence of any special differentiation in this zone (Fig. 10, D3).

At a level of the telencephalon caudal to that described in the preceding figure, there was noted the D2 al pallial zone (Fig. 11, D2 al). Dorsal to this zone the D2 am telencephalic zone could be seen (Fig. 11, D2 am). Dorsomedially there could be demarcated the D3 pallial zone; which as yet showed no special degree of cortical differentiation (Fig. 11, D3). At the periphery of the lateral extremity of the telencephalon, there could be noted a small band like group of cells, which formed the pallial zone $\mathrm{D}(2+1) \mathrm{c}$ (Fig. 11, $\mathrm{D}(2+1) \mathrm{c})$. At the ventrolateral extremity of the telencephaic wall a thin band like area of closely arranged cells could be seen. This cellular area forms the primordium or forerunner of the future periamygdalar cortex (Fig. 11, Bs. vlp. pr.). Just ventral to this cellular area at the ventrolateral border of the telencephalon, the sulcus telo-diencephalicus could be seen (Fg. 11, std.). The preoptic recess could be noted in the ventral midline (Fig. 11, r. p. o.). Lying just ventral to the preoptic recess the rostral extremity of the optic chiasm could be seen (Fig. 11, Opt. ch.).

The most rostral extremity of the hypothalamus could be noted at this level; and at its medial border the the sulcus intraencephalicus anterior could be seen (Fig. 11, Si.). A small part of the most rostral part of the ventral thalamic zone could be noted (Fig. 11 v. th.). Dorsomedially at this level of the telencephalon, the rostral extremity of the doral thalamic zone could be observed (Fig. 11, t.d.). Dorsally and in the midline the velum transversum could be seen (Fig. 11, v. t.). Lying medial to the $\mathrm{D}(2+1) \mathrm{c}$ zone the remaining part of the pallial D1 zone could still be noted (Fig. 11, D1). Ventrally the basal telencephalic zones of $\mathrm{B} 1$ and $\mathrm{B} 2$ could be noted (Fig. 11, B1 and B2).

\section{Trichosurus vulpecula, $24 \mathrm{~mm}$}

In the telencephalon of the $24 \mathrm{~mm}$ Trichosurus vulpecula embryo there could be noted dorsomedially the D2 am pallial zone. In the D2 am zone there could be noted a quite thick inner mantle cell layer, and a more loosely arranged outer intermediate zone (Fig. 12, 2. i. and 3) The D2 am pallial zone showed evidence of an inner ependymal cell layer. Lying peripheral to the intermediate zone of the mantle cell layer there could be seen a quite distinct thin cellular layer, which forms the primordial granular or cortical zone (Fig. 12,, P.G.). Lying peripheral to this cell layer, the marginal zone could be noted (Fig. 12, M. G.).

Thus there could be noted at this stage the four layer stage of cortical development noted by Tilney and Kubie (1931) in the $13 \mathrm{~mm}$ cat embryo. Kuhlenbeck and Domarus (1920) have shown a four layer stage in Lacerta Agilis, which is comparable to a similar four layer stage in the cerebral cortex of the $24 \mathrm{~mm}$ Trichosurus vulpecula embryo. According to Tilney and Kubie (1931), the conditions at this stage point to the recapitulation of the reptilian conditions in the mammalian brain.

Just ventrolateral to the $\mathrm{D} 2$ al pallial zone, there could be observed the pallial area $\mathrm{D}(2+1) \mathrm{b}$ (Fig. $12, \mathrm{D}(2+1) \mathrm{b})$. At uhis stage there could be demarcated in the $D(2+1) b$ area an ependymall ayer, an inner mantle layer, an outer intermediate subdivision of the mantle layer, and a 
band like cell group, which forms the primordial granular or cortical zone. There could also be seen a thin marginal layer. Just ventral to the $\mathrm{D}(2+1) \mathrm{b}$ zone, there could be observed a group of cells which forms the pallial area $\mathrm{D}(2+1)$ c. This area formed a distinct thin band of closely packed cells (Fig. 12, $\mathrm{D}(2+1) \mathrm{c}$ ). In the dorsomedial sector of the telencephalic wall there could be noted the D3 pallial zone (Fig. 12, D3). As yet no evidence of any special cortical differentiation could be noted in the D3 zone. The remaining part of the D1 pallial zone had become thickened and projected into the lateral ventricle (Fig. 12, D1). At the ventrolateral border of the telencephalon there could be demarcated a thin group of closely arranged cells. This cellular area forms the primordium of the future tuburculum olfactorium (Fig. 12, Bs. vla.pr.). Ventromedially the B3 basal telencephalic none could be noted. Just dorsal to the B3 zone, there could be seen the B4 basal zone (Fig. 12, B3 and B4).

At the caudak level of the telencephalon and just ventrolateral to the D2 am pallial zone, there could be seen the pallial D2 al zone (Fig 13, D2 al). In the telencephalic wall of the D2 al zone there could be observed an inner ependymal layer and a mantle layer with an outer intermediate subdivision. Lying just peripheral to this layer, there could be seen a well defined primordial granular or cortical zone, as well as an outer thin marginal layer.

Lying ventrolateral to the D2 alpallial zone, there could be noted the $\mathrm{D}(2+1) \mathrm{b}$ pallial zone (Fig. 13, D $(2+1) \mathrm{b}$ ). Lying just ventral to the $\mathrm{D}(2+1) \mathrm{b}$ zone there was observed a thin band like area of closely arranged cells. This cell area forms the pallial $D(2+1)$ c zone (Fig 13 , $\mathrm{D}(2+1) \mathrm{c})$. In the ventrolateral extremity of this level of the telencephalon there could be seen an area of closely arranged cells. This cellular area forms the primordium of the future amygdalar nuclear complex (Fg. 13, am. pr.). Dorsally and clese to the midline, there could be demarcated the rostral extremity of the diencephalon.

At this level the rostral extremity of the dorsal thalamic zone and the sulcus medius could be noted (Fig. 13, t. d. and s. m.). Ventrally there could be seen the rostral extremity of the ventral thalamus, as well as the sulcus ventralis thalami (Fg. 13, t. v. and s. v.). Ventral to this zone the rostral extremity of the hypothalamic diencephalic zone could be demarcated (Fig. 13, hy). In the dorsolateral extremity of the hypothalmic zone there could be noted an area of cellular condensation; which forms the primordium of the future globus pallidus (Fig. 13, pal. pr.). According to Kuhlenbeck (1924 and 1929) the primordium of the globus pallidus is derived from the dorsolateral part of the hypothalamic diencephalic zone.

At the ventrolateral border of the telencephalon, there could be seen the sulcus telo-diencephalicus ( $\mathrm{Fg} .13$, std.). Lying peripheral to the primordium of the amygdala there could be noted at the periphery of the telencephalic wall, an area of closely arranged cells; which forms an area of transition between the tuberculum olfactorium and the periamygdalar cortex (Fig. 13, ar. trns. vls. pr.). Dorsomedially the D3 pallial telencephalic zone could be observed. As yet this pallial zone showed no evidence of any special degree of cortical differentiation (Fig. 13, D3). The caudal part of the B3 basal telencephalic zone could still be noted (Fg. 13, B3). The B1 and B2 basal telencephalic zones were closely connected at this level (Fg. 13, B1 and B2). The internal capsule could be demarcated (Fg. 13, c. i.). 
According to Kuhlenbeck (1924, 1925, and 1929) the putamen takes origin from the medial part of the nucleus epibasalis anterior or the epistriatum; which according to Kuhlenbeck is comparable to the anterior portion of the hypopallial ridge of reptiles. Kuhlenbeck indicated that the putamen is derived from the medial parts of the joined zones D1, B1 and B2. An early stage of the claustrum could be observed at this level (Fig. 13, C1). According to Kuhlenbeck (1924 and 1929), the claustrum is derived from the lateral part of the nucleus epibasalis anterior or the epistriatum. Kuhlenbeck (1924 and 1929) indicated that the claustrum is derived from the lateral part of the joined zones D1, B1 and B2. At the ventrolateral extremity of the caudal level of the forebrain an early stage of the periamygdalar cortex could be seen (Fg. 14, Bs. vlp.). At the caudal level of the forebrain the sulcus lateris infundibuli could be noted (Fig. 14, s. i. a.). An early stage of the putamen as well as the primordium of the globus pallidus could still be noted at this level (Fig. 14 pu. and pal.pr). An early stage of the claustrum could also be noted at this level (Fg. 14, $\mathrm{Cl}$ ).

\section{Perameles nasuta, $23 \mathrm{~mm}$}

The $23 \mathrm{~mm}$ Perameles nasuta embryo represents a stage of development of the telencephalon, which was more advanced than that of the stage previously described. At the level of the anterior commissure the rostral extremity of the hypothalamus could be noted. The fissure fdl, or the fissure dorsalis number 1 , and the fissure $\mathrm{fd} 2$ or the fissure dorsalis number 2 , could be seen on the lateral surface of the lateral ventricular wall (Fig. 15, fd. 1 and fd.2). The sulcus fdl demarcates the zones D1 and B1, and the sulcus $\mathrm{fd} 2$ or fissure dorsalis number 2 demarcates the telencephalic pallial zones D2 and D1.
The pallial zone D2 al was well defined and showed an advance in the degree of differentiation, as compared with that of the previously described stage (Fig. 15, $\mathrm{D} 2 \mathrm{al})$. In the $\mathrm{D} 2$ al zone the telencephalic wall consisted of an inner ependymal layer, and an inner subdivision of the mantle layer, which had an outer intermediate subdivision consisting of more loosely arranged cells (Fig. 15, 1, 2. i. and 3). Lying peripheral to this layer, there could be noted a primordial granular or cortical zone (Fg. 15, P. G.). This cortical zone was thicker and better defined than at the stage previously described. Just peripheral to this zone a thin clear marginal layer could be seen (Fig. 15, M. G.). Lying ventral to the D2 al zone there could be demarcated the pallial zone of $\mathrm{D}(2+1) \mathrm{b}$. The pallial zone $\mathrm{D}(2+1) \mathrm{b}$ takes origin from the basolateral extremity of the D2 al zone (Fg. 15, $\mathrm{D}(2+1) \mathrm{b})$. Accoding to Kuhlenbeck (1924 and 1929), the pallial zone $D(2+1) b$ later becomes the insular cortex. In the telencephalic wall of the area $\mathrm{D}(2+1) \mathrm{b}$ there could be noted a thick inner subdivision of the mantle layer with an outer intermediate subdivision. Peripheral to this layer there could be demarcated a primordial granular or cortical zone, and an outer marginal layer. Lying just ventral to the $\mathrm{D}(2+1) \mathrm{b}$ zone, there could be delimited a band like group of cells which forms the pallial area $\mathrm{D}(2+1) \mathrm{c}$ (Fg. 15, D $(2+1)$ c.

At this stage the D2 am zone consisted of four layers namely an inner ependymal layer, an inner subdivision of the mantle cell layer, which was quite thick, and showed evidence of having an outer intermediate subdivision of more loosely arranged cells (Fg. 15, 1, 2.i., and 3). Lying peripheral to the mantle layer, there could be noted awell defined primordial granular or cortical zone, and thin clear marginal zone (Fg. 15, P.G. 
and M.G.). Lying ventromedial to the D2 am zone there could be seen the pallial D3 zone. It showed four cell layers, namely an inner ependymal layer, an inner mantle cell layer with an outer intermediate subdivision, which was not as distinct as in the D2 al zone. Peripheral to this layer a thin primordial granular or cortical zone and a thin marginal layer could be noted in this area.

At this level there could be demarcated a cell mass in the medial part of the joined zones D1, B1, and B2, which forms the epistriatum. In this area there could be seen an area of cellular condensation, whith forms an early stage of the caudate nucleus (Fig. 15, N. Cau.). Just ventrolateral to the caudate nucleus, there could be seen an area of cellular condensation which forms an early stage of the putamen (Fig. 15, pu.). Ventrally and slightly lateral to the putamen there could be noted an area of cellular condensation which forms an early stage of the claustrum (Fig. 15, Cl.). At the dorsolateral extremity of the hypothalamus there could be noted an area of cell condensation. This cellular area forms the primordium of the globus pallidus (Fig. 15, pal. pr.). At the ventrolateral extremity of the telencephalon there could be observed an area of cellular condensation lying ventrolateral to the anterior commissure. This cellular area forms the primordium of the future amygdala (Fig. 15, am. pr.). Slightly dorsal and lateral to the primordium of the amygdala there could be noted a thin hand like group of closely arranged cells. This cell mass forms the periamygdalar cortex (Fig. 15, Bs. vlp.). Lying ventral to the periamygdalar cortex, there could be seen at the ventrolateral extremity of the telencephalon the sulcus telodiencephalicus (Fig. 15, std.). In the ventromedial part of the telencephalon there could be observed the basal telen- cephalic zone B3. According to Kuhlenbeck (1969), this cellular area becomes later on the nucleus basimedialis inferior. The besal telencephalic zone B4 could also be noted, lying just dorsal to the $B 3$ zone (Fig. 15, B3 and B4).

\section{Trichosurus vulpecula, $30 \mathrm{~mm}$}

At the most rostral level of the telencephalon, the D1 pallial telencephalic zone could still be demarcated. Ventrally the basal telencephalic zones $\mathrm{B} 1$ and $\mathrm{B} 2$ were fused at this level (Fig. 16, B1+B2). The basal telencephalic zone B3 could likewise be demarcated at the ventromedial area of the telencephalic wall. Just dorsal to the basal telencephalic B3 zone there could be noted the B4 basal telneephalic zone (Fig. 16, B3 and B4). Ventrally an early stage of the tuberculum olfactorium could be seen, lying in the ventral part of the telencephalon (Fig. 16, Bs. vla.). The tuberculum olfactorium at this level forms a fairly large discrete group of closely arranged cells.

Dorsally there could be demarcated the rostral part of the D2 al telencephalic zone (Fig. 16, D2 al). There could be seen in the telencephalic wall of the D2 al zone an inner ependymal layer, an inner part of the mantle layer, and an outer subdivision or the intermediate zone of the mantle layer. Lying peripheral to this intermediate part of the mantle layer there could be seen a fairly thick primordial granular or cortical layer, which was considerably thicker than in the previously described stage. A relatively thin outer marginal layer could be demarcated. In the dorsomedial part of the telencephalon there could be noted the rostral part of the D2 am pallial telencephalic zone. Ventrolateral to the D2 al zone, there could be demarcated a quite discrete hand like group of closely packed cells, which lies in the peripheral part of this level of the telencephalon. 
This cell mass forms the telencephalic cell area of $\mathrm{D}(2+1) \mathrm{c}+\mathrm{B} 1$. This cellular area forms the praepiriform cortex (Fig. $16, \mathrm{D}(2+1) \mathrm{c}+\mathrm{B} 1)$. Aeeording to Kuhlenbeck (1924 and 1929) the praepiriform cortex is derived from the rostral part of the pallial area of $D(2+1)$ c.

The D3 pallial telencephalic area could be seen at this level. It showed evidence of a quite thick telencephalic wall. The telencephalic wall in this area consisted of an inner ependymal layer, an inner part of the mantle layer, and an outer more loosely arranged intermediate subdivision of the mantle cell layer. Lying peripheral to this layer there could be noted a fairly well defined primordial granular or cortical layer. A thin marginal layer could also be seen (Fig. 16, D3). At the level of the anterior commissure, the D2 al pallial telencephalic area consisted of an inner ependymal layer and an inner mantle layer with an intermediate outer subdivision, consisting of loosely arranged cells. Just peripheral to this layer, a quite thick primordial granular or cortical zone could be noted (Fig. 17, D2 al). A thin clear marginal zone could also be seen (Fig. 17, 1, 2. i., 3, P. G., M. G.)

Lying just ventral to the D2 al pallial zone there could be observed the pallial telencephalic zone of $\mathrm{D}(2+1) \mathrm{b}$ (Fig. 17, $D(2+1) b)$. The telencephalic wall in this area showed evidence of having an inner mantle layer with an outer intermediate subdivision; and peripheral to this layer there was a primordial granular or cortical layer. This layer was not as thick, nor was it as sharply defined as in the D2 al zone. Ventral to this zone there could be seen the $D(2+1) c$ pallial telencephalic zone, which formed a band like group of closely packed cells (Fig. 17, $\mathrm{D}(2+1) \mathrm{c}$ ).

Dorsomedially there could be noted the D2 am pallial zone. The telencephalic wall of the D2 am zone showed an inner ependymal layer, an inner mantle cell layer with an intermediate outer subdivision, a primordial granular or cortical layer, and a thin marginal layer (Fig. 17, D2 am). Lying just ventral to the D2 am zone there could be seen the D3 zone (Fig. 17, D3). The D3 zone consisted of an inner ependymal layer, and an inner mantle layer with an intermediate outer subdivision; and a thin primordial granular or cortical layer, as well as a marginal layer. However there could not be demarcated in this zone as yet, either a cornu Ammonis or a dentate fascia. The pallial zone D1 and the basal telencephalic zones B1 and B2 could still be demarcated (Fig. 17, D1, B1 and B2). The pallial zone D1 had joined the basal zones B1 and B2. According to Kuhlenbeck (1924 and 1929), the anterior part of the telencephalic D1, B1, and B2 zones becomes the nucleus epibasalis anterior. The medial part of the nucleus epibasalis anterior or the epistriatum is equivalent to the neostriatum of Kappers (1921).

An early staga of the claustrum formed a band like group of closely packed cells, lying in the lateral part of the nucleus epibasalis anterior or the epistriatum (Fig. 17, C1.). Dorsomedially an early stage of the caudate nucleus could be demarcated at this level. It formed a cell mass of densely packed cells (Fig. 17, N. Cau.). Ventrolateral to the caudate nucleus a cell mass consisting of closely packed cells could be seen, which formed an early stage of the putamen (Fig. 17, pu.). According to Kuhlenbeck (1924 and 1929), the medial part of the nucleus epibasalis anterior or the epistriatum gives rise to both the caudate nucleus and putamen. The internal capsule and the anterior commissure could be demarcated at this level (Fig. 17, c.i. and c. a.). Just ventral to the anterior commissure there could be seen a group of closely arranged cells. This cell mass forms the primordium of the globus pallidus (Fig. 
17, pal. pr.). At the ventromedial border of this level of the telencephalon there could be noted the sulcus telo-diencephalicus (Fig. 17, std.).

In the ventromedial part of the telencephalon a group of closely packed cells could be seen. This cell mass forms the primordium of the future amygdala (Fig. 17 , am. pr.). Ventromedially in the midline there could be seen the preoptic recess (Fig. 17, r. p. o.). At the periphery of the ventrolateral extremity of the telencephalon, there could be seen a band like cell mass. This cell mass forms the transitional area between the tuberculum olfactorium and the periamygdalar cortex (Fig. 17, ar.trns. vls.). Ventromedially there could be noted at this level the rostral extremity of the hypothalamus (Fig. 17, hy.). In the ventromedial part of the telencephalon there could be seen a cell mass which forms the basal telencephalic area of B3. Dorsal to the B3 zone there could be observed the B4 basal telencephalic zone (Fig. 17, B3 and B4). Kuhlenbeck (1969) indicated that the derivation of the B4 zone can be grouped under the term nucleus basimedialis superior. According to Kuhlenbeck (1969) the nucleus basimedialis superior takes origin from the B4 basal zone. However, Kuhlenbeck and other authors have also designated these cell masses derived from the $B 4$ zone as the septal nuclei.

In the telencephalon at a slightly more caudal level, there was seen ventrally in the midline the optic chiasma and at the ventrolateral extremity of the telencephalon there could be noted the sulcus telo-diencephalicus (Fig. 18, Opt.ch. and std.). Ventrally and close to the midline there could be seen the hypothalamic zone (Fig. 18, hy.). Lying just above the hypothalamic zone there could be seen the rostral level of the ventral thalamic zone (Fig. 18, t. v.). Dorsal to the ventral thalamic zone the rostral extremity of the dorsal thalamic zone could be noted (Fig. 18, t. d.).

In the ventrolateral extremity of the right side of the telencephalon, just above the sulcus telo-diencephalicus there could be seen a group of closely arranged cells. This cell mass forms the area of transition between the tuberculum olfactorium and the periamygdalar cortex (Fig. 18, ar. trns. vls.). On the left side of the telencephalon at the ventrolateral extremity of the telencephalon a closely arranged cell mass could be seen, which forms the periamygdalar cortex (Fig. 18, Bs. vlp.). This cell mass forms at this stage a band like cell group lying close to the periphery of this part of the telencephalon. Lying just dorsomedial to the periamygdalar cortex there could be seen a fairly large oval shaped cell group. This cell mass is a closely packed group of cells, which forms the primordium of the future nucleus amygdala (Fig. 18, am.pr.). According to Kuhlenbeck 1924 and 1929, the nucleus epibasalis posterior in mammals gives rise to the main portion of the amygdaloid nuclear complex. Kuhlenbeck 1929 indicated that the reptilian hypopallial ridge was comparable to the nucleus epibasalis anterior and the nucleus epibasalis posterior in mammals.

Just lateral to the dorsolateral extremity of the hypothalamic zone there could be noted a graup of closely arranged cells. This cell mass forms the primordium of the globus pallidus (Fig. 18, pal.pr.). Dorsally and close to the midline a fairly large cell mass of clesely packed cells could be seen on the left side of the figue. This cell mass forms an early stage of the caudate nucleus (Fig. 18, N. Cau.). Ventrolateral to the caudate nucleus there could be noted a large group of closely arranged cells, which forms an early stage of the putamen (Fig. 18, pu.). Just lateral to the putamen 
a thin band like cell mass could be seen, which forms the claustrum (Fig. 18, C1.).

Just dorsal and lateral to the rostral extremity of the dorsal thalamus, there could be observed the lamina affixa (Fig. 18, 1. af.). The lamina affixa forms a thin membranous structure, which is a part of the ependymal lining of the lateral ventricle. It is superimposed on the lateral part of the thalamus. Lying just lateral to the ventral part of the dorsal thalamus and just ventral to the corpus striatum complex, there could be noted the sulcus terminalis (Fig. 18, s. term.). The sulcus medius which demarcates the dorsal from the ventral thalamus; and the sulcus ventralis which demarcates the ventral thalamus from the hypothalamus, could still be noted (Fig. 18, s. m. and s. v.). The internal capsule could be demarcated at this level (Fig. 18, c. i.). There was as yet no definite cornu Ammonis or a dentate fascia at the $30 \mathrm{~mm}$ stage. However, an ill defined cell agglomeration could be seen, at the most caudal level of the telencephalon in the D3 zone, which forms the primordium of the cornu Ammonis and the dentate fascia (Fig. 19, Pr.ah. and Pr.fd.). The caudate nucleus and the putamen could be readily demarcated at this level (Fig. 19, N.Cau. and pu.). The primordium of the globus pallidus could also be noted; and the claustrum could still be noted at this level (Fig. 19, pal. pr.and C1.). The primordium of the amygdala and the periamygdalar cortex could be seen at this level (Fig. 19, am. pr. and Bs. vlp.).

\section{Trichosurus vulpecula, $40 \mathrm{~mm}$}

At the level of the rostral part of the anterior commissure in the D3 pallial telencephalic zone, there could be demarcated the cornu Ammonis and the dentate fascia (Fg. 20, ah. and fd.). There could be noted in the dentate fascia closely arranged granule cells, which however were not as well defined as in the adult state. The pyramidal cells in the cornu Ammonis were more loosely arranged than the cells in the dentate fascia. The pyramidal cells of the cornu Ammonis could be vaguely demarcated at this stage. At the lateral extremity of the cornu Ammonis the pyramidal cells could be more readily demarcated and at the lateral extremity of the cornu Ammonis there could be noted a scattering of the pyramidal cells.

Dorsal to the cornu Ammonis of the hippocampal cortex there could be seen in the D2 am zone an early stage of the parahippocampal cortex. In the parahippocampal cortex there could be vaguely seen a poorly defined outer densely arranged layer of cells, and a more loosely arranged inner layer of cells (Fig. 20, D2 am). This foreshadowed the adult form of parahippocampal cortex. There could be noted in the D2 al zone an early stage of the neocortex; which had an inner ependymal layer, an inner part of the mantle zone, and an outer or intermediate part of the mantle zone was seen. Internal to the pyramidal layer was seen a poorly and vaguely defined internal granular layer of loosely arranged cells. The pyramidal layer had become quite thick; and peripheral to this layer a vaguely defined external granular layer, as well as a marginal layer, was noted (Fig. 20, D2 al).

Just ventral to the D2 al pallial zone there could be seen tne pallial zone $\mathrm{D}(2+1) \mathrm{b}$. This pallial area is a subregion of the neocortex, which differentiates later to form the adult insular cortex (Fg. 20, D $(2+1) b)$. Just ventral to the pallial $\mathrm{D}(2+1 \mathrm{~b}$ zone there could be noted the pallial $\mathrm{D}(2+1)$ c zone. The $\mathrm{D}(2+1) \mathrm{c}$ zone formed a well defined band like cell mass consisting of closely packed cells, which began to resemble the pyriform 
cortex of the adult state (Fig. $20, \mathrm{D}(2+1) \mathrm{c}$ ).

In the basal telencephalic B4 zone an early stage of the nucleus basimedialis superior was noted (Fig. 20, Nu. Basm. S.). In the B3 zone an early stage of the nucleus basimedialis inferior was noted (Fg. 20, Nu. Basm. in.). According to Kuhlenbeck (1969), the derivatives of the B4 basal zone could be indicated by the collective term of the nucleus basimedialis superior. Ventral to the basal B4 zone there could be seen the B3 basal zone, in which an early stage of the nucleus basimedialis inferior was noted. According to Kuhlenbeck (1969), the derivatives of B3 basal zone could be termed the nucleus basimedialis inferior. These derivatives of the B3 zone comprise the bed nucleus of the anterior commissure and the stria terminalis, as well as the nucleus acumbens in the adult state.

The sulcus in the ventricular wall namely fd. 1 could be noted (Fig. 20, fd. 1). It demarcates the lower boundary of the D1 zone. Just dorsal to this sulcus there could be noted the sulcus fd.2, which bounds the lower boundary of the D2 zone (Fig. 20, fd. 2). The sulcus fd. 4 could also be noted on the medial ventricular wall. It demarcates the D3 from the B4 zone (Fg. 20, fd. 4). The rostral part of the anterior commissure and the internal capsule could be observed at this level (Fig. 20, c. a. and c. i.). Just lateral to the internal capsule there could be noted a large oval cell mass consisting of closely packed cells, which forms the putamen. At this stage it began to resemble that of the adult state (Fig. 20, pu.). Just lateral to the putamen there could be noted a band like cell mass; which forms clastrum (Fig. 20, C1.).

Just ventral to the putamen there could be seen a group of rather loosely arranged cells. This cell mass forms the rostral part of the globus pallidus (Fig. 20, pal.). It begins to resemble the globus pallidus of the adult state. Just ventromedial to the globus pallidus there could be seen a fairly large oval cell mass. This cell mass forms an early stage of the nucleus amygdala (Fig. 20, nu. am.). According to Kuhlenbeck (1924 and 1929), the nucleus amygdalae is derived from the caudal parts of the zones D1, B1, and B2. Just ventrolateral to the nucleus amygdalae there could be seen a poorly demarcated band like cell mass. This cell mass forms an early stage of the periamygdalar cortex (Fig. 20, Bs. vip.). According to Kuhlenbeck (1924 and 1929), the periamygdalar cortex is derived from the basal zones B1, B2, and B3. At the level of the middle of the anterior commissure, in the ventromedial part of the dorsal extremity of the telencephalic wall there could be demarcated in the D3 zone the Ammon's horn and the dentate fascia, which resembled that of the rostral anterior commissural level of the telencephalon (Fig. 21, ah. and fd.).

Dorsal to the hippocampal cortex there could be seen in the D2 am zone an early stage of the parahippocampal cortex. There could be vaguely demarcated an inner cell layer of loosely arranged cells and a densely packed outer layer of cells. The inner layer of the parahippocampal cortex abuts on the cornu Ammonis. According to Kuhlenbeck (1960), the outer cell layer of the parahippocampal cortex is continuous with, or may correspond to layers II, III, and IV of the neocortex; and the inner cell layer would then correspond to layers V and VI of the neocortex. According to Kuhlenbeck (1924, 1925, and 1929), the primordium neopallii is an early development of the D2 al zone in reptiles. Thus, he indicated that the neocortex is a further derivation of the D2 al zone.

In the ventrolateral part of the telencephalon there could be observed a large oval shaped mass of closely arranged 
cells. This cell group forms an early stage of the nucleus amygdalae (Fig. 21, nu. am.). The nucleus amygdala shows as yet, no evidence of differentiation of the various amygdalar nuclei. Lying just ventral to the nucleus amygdalae there could be seen a band like group of closely arranged cells. This cell mass forms an early stage of the periamygdalar cortex (Fig. 21, Bs. vlp.). At the ventral margin of the ventromedial extremity of the telencephalon there could be seen the sulcus telo-diencephalicus (Fig. 21, std.). Lying. ventral to the derivatives of the D3 zone there could be noted the caudal part of the B4 basal telencephalic zone, Lying just ventral to the B4 basal zone there could be seen the caudal part of the B3 basal zone.

At this level the sulcus fd. 1, which demarcates the pallial zone $\mathrm{D} 1$ from the fused basal zones $B 1+B 2$ could be seen in the lateral ventricular wall (Fig. 21, fd.1). There could still be demarcated, the D1 zone and the fused basal zones $\mathrm{B} 1+\mathrm{B} 2$. At this stage the caudate nucleus could be definitely demarcated. Just lateral to the internal capsule there could be noted a large oval shaped mass of closely packed cells. This cell mass forms an early stage of the putamen (Fig. 21, pu.). In form it begins to foreshadow the putamen of the adult state. Just ventromedial to the putamen there could be seen an oval shaped mass of closely arranged cells. This cell mass forms an early stage of the globus pallidus; which likewise begins to foreshadow the globus pallidus of the adult state (Fig. 21, pal.). Ventrally and close to the midline, the anterior level of the hypothalamus, the third ventricle, and the optic chiasm could be seen. Lying just lateral to the putamen there could be observed a well defined band like cell mass of closely packed cells. This group forms the claustrum (Fig. 21,
Cl.).

At the caudal level of the telencephalon. in the dorsomedial part of the telencephalon there could be observed the Ammon's horn or the cornu Ammonis and the dentate fascia (Fig. 22, ah. and fd.), which resembled that noted in the more rostral levels of the telencephalon. Ventral to the $D(2+1) b$ zone there could be noted the pallial zone $\mathrm{D}(2+1) \mathrm{c}$. It formed a quite thick band like cell group, which began to resemble in form the adult pyriform cortex (Fig. 22, D $(2+1)$ c). In the ventrolateral extremity of the telencephalon there could be seen a large oval shaped cell mass consisting of closely packed cells. This cell mass forms an early stage of the nucleus amygdala (Fig. 22, nu. am.). No evidence of differentiation of the various amygdalar nuclei could as yet be seen in the nucleus amygdala.

Just ventral to the nucleus amygdalae there could be seen a band like group of cells which forms an early stage of the periamygdalar cortex (Fig. 22, Bs. vlp.). At the ventromedial extremity of the telencephalon there could be observed the sulcus telo-diencephalicus (Fig. 22, std.). Dorsally and close to the midline the rostral part of the epithalamus could be seen (Fig. 22, et.). Ventrally and close to the midline the rostral part of the hypothalamus and supraoptic nucleus could be seen (Fig. 22, hy. and So.n.). Ventrally and close to the midline the optic chiasm could be seen; and the foramen of Munro could likewise be noted at this level (fig. 22, F. M.).

The caudate nucleus could be demarcated and it began to resemble the caudate nucleus of the adult state (Fg. 22, N. Cau.). Ventrolateral to the caudate nucleus there could be seen a large oval cell mass, consisting of closely packed cell, which forms the putamen (Fg. 22, pu.). Ventromedial to the putamen there could be 
demarcated a fairly large mass of rather closely arranged cells. This cell group forms the globus pallidus, which began to resemble in form that noted in the adult stage (Fg. 22, pal.). According to Kuhlenbeck (1924 and 1929), the primordium of the globus pallidus, which is derived from the dorsolateral part of the hypothalamic zone includes the anterior entopeduncular nucleus. He further stated that the anlage or primordium of the globus pallidus migrates rostrally, and at the later stages joins the putamen and caudate nucleus to become the adult form of mammalian globous pallidus. $\mathrm{He}$ also indicated that in the higher mammals the globus pallidus receives some contributions of the telencephalic matrix namely, from the zones D1, B1, and B2. In the $40 \mathrm{~mm}$ stage, the globus pallidus had migrated rostrally to join the putamen and caudate nucleus, and had become the adult form of globus pallidus.

\section{Trichosurus vulpecula, $41 \mathrm{~mm}$}

In the dorsomedial part of the telencephalic wall, at the most rostral extremity of the telencephalon, there could be noted the D2 am pallial zone. The outer and inner cell layers of the D2 am zone were however well defined at this stage. Just ventrolateral to the D2 am zone there could be noted the pallial D2 al zone (Fg. 23, D2 al). The telencephalic wall in the D2 al zone showed an inner ependymal layer and an inner part of the mantle layer, just peripheral to it. Just peripheral to this layer there could be seen an outer considerably wider intermediate part of the mantle layer, containing loosely arranged cells. There could be seen the pyramidal layer, which was thicker than at the previously described stage. Just internal to the pyramidal layer a well defined loosely arranged internal granular layer could be seen. Just peripheral to the pyramidal layer a rather poorly defined external granular layer could be noted as well as a marginal layer. The $\mathrm{D}(2+1) \mathrm{b}$ zone resembled that of the $\mathrm{D} 2$ al zone this stage ( $\mathrm{Fg} .23, \mathrm{D}(2+1) \mathrm{b})$.

Lying just ventral to the $D(2+1) b$ pallial zone there could be seen the pallial zone $\mathrm{D}(2+1) \mathrm{c}+\mathrm{B} 1$. This pallial area consisted of a band like group of closely packed cells. This cell group gives rise to the praepiriform cortex. It lies at the periphery of the telencephalic wall. At this stage this cell mass ls better defined and begins to resemble that of the adult state (Fig. 23, $\mathrm{D}(2+1) \mathrm{c}+\mathrm{B} 1$ ). At the ventral extremity of the telencephalon there could be seen a fairly thick band like cell group, which forms the tuberculum olfactorium (Fig. 23, Bs. vla.).

At the ventromedial extremity of the telencephalon there could be seen a thin band of fibers. This fiber bundle forms the diagonal band of Broca, which begins to resemble that of the adult state (Fig. 23, Bs. d.). Just below tne D3 pallial zone there could be noted the B4 basal telencephalic zone. This area begins to resemble the nucleus basimedialis superior of the adult state (Fig. 23, Nu. Basm. S.). Just ventral to the $B 4$ zone there could be seen the B3 basal zone. This cell group forms the nucleus basimedialis inferior; which likewise begins to resemble that of the adult state (Fig. 23, Nu. Basm. in).

In the dorsomedial portion of the telencephalon, at a precommissural level caudal to that of the previously described figure, the D2 am pallial zone could be noted. It consisted of an inner well defined layer of loosely arranged cells and an outer layer of densely packed cells, as well as an outer zonal or molecular layer. The D2 am zone begins to resemble that of the adult parahippocampal cortex (Fig. 24, Pah. Ct.). Just ventral to the D2 am pallial zone there could be seen the D3 
pallial zone (Fig. 24, D3). At the dorsolateral extremity of the telencephalon there could be observed the D2 al zone (Fig. 24, D2 al). The telencephalic wall in this arera consisted of an inner ependymal layer, peripheral to which could be seen the mantle layer. The mantle layer consisted of an inner layer of densely packed cells. Peripheral to this layer there could be seen an outer intermediate layer, containing loosely arranged cells. At the peripheral part of the telencephalic wall there could be observed the pyramidal layer which was quite well defined. Internal to the pyramidal layer a loosely arranged well defined internal granular cell layer could be demarcated. Just peripheral to the pyramidal layer a poorly defined external granular layer was seen, as well as an outer marginal layer.

Just ventral to the $D(2+1) b$ zone there could be seen, at the ventrolateral part of the telencephalic wall, a band like cell mass of closely packed cells, which forms the $\mathrm{D}(2+1) \mathrm{c}$ zone (Fig. $24, \mathrm{D}(2+1) \mathrm{c}$ ). In the ventral part of the telencephalon, at this level, there could be observed a fairly thick band like group of closely arranged cells. This cell mass forms the tuberculum olfactorium, which had begun to resemble that of the adult state (Fig. 24 , Bs. vla.). At the ventromedial extremity of the telencephalon there could be demarcated the diagonal band of Broca, which began to resemble that of the adult state (Fig. 24, Bs. d.).

Just ventral to the D3 zone, there could be seen the B4 basal telencephalic zone. The B4 zone at this stage begins to resemble the nucleus basimedialis superior of the adult state (Fig. 24, Nu. Basm. S.). Just ventral to the $B 4$ zone there could be seen the B3 basal zone. In the B3 basal zone there was noted the nucleus basimedialis inferior. The nucleus basimedialis inferior at this stage began to resemble that of the adult form (Fig. 24,
Nu. Basm. in.). At the caudal level of the precommissural level of the telencephalon there was noted in the D3 pallial zone the precommissural hippocampus (Fig. 25, prec. hipp.). It formed a single cell area in which the fused ah. and fd. areas were a single zone. No evidence of a differentiation into a separate Ammon's horn and a dentate fascia was seen. At the same caudal precommissural level of the telencephalon, there was noted in the dorsomedial part of the telencephalon the D2 am pallial zone. In the D2 am pallial zone there was noted a well defined inner layer of loosely arranged cells and a well defined outer layer of densely arranged cells. This area had begun to resemble the adult parahippocampal cortex (Fig. 25, Pah. Ct.).

In the dorsolateral part of the telencephalon there could be seen the D2 al pallial zone. In the telencephalic wall of the D2 al zone there could be observed an ependymal and an inner mantle layer. The mantle layer consisted of an inner layer of densely packed cells and an outer intermediate layer of more loosely arranged cells (Fg. 25, 1, 2. i. and 3). There was noted an outer pyramidal layer which was quite thick (Fig. 25, Pyr.). Internal to the pyramidal layer was noted a more loosely arranged internal granular layer (Fig. 25, I. G.). There was noted peripheral to the pyramidal layer a thinner external granular layer and an outer marginal layer (Fig. 25, E. G. and M.G.). According to Tilney and Kubie (1931) the pyramidal layer, internal granular layer, and external granular layer are all derived from the primordial granular or cortical layer. Ventral to the $\mathrm{D}(2+1) \mathrm{b}$ zone there could be seen the pallial $D(2+1)$ c zone. This pallial zone began to resemble the adult form of the pyriform cortex (Fig. 25, P. L.).

At the ventral extremity of this level of the telencephalon there could be noted 
a band like group of closely arranged cells. This cell mass forms the tuberculum olfactorium, which began to resemble that of the adult state (Fig. 25, Bs. vla,). Just ventral to the D3 zone there could be seen the nucleus basimedialis superior or septal nuclei of Kuhlenbeck (1969) and other authors, which began to resemble those of the adult state (Fig. 25, Nu. Basm. S.). Ventral to the B4 basal zone there could be noted the B3 basal zone, which forms the nucleus basimedialis inferior. The nucleus basimedialis inferior likewise began to resemble that of the adult state (Fg. 25, Nu. Basm. in.). Medial to the pallial zone $\mathrm{D}(2+1) \mathrm{b}$ there could be observed a thin band like cell mass. This cell group forms a well defined stage of the claustrum (Fg. 25, Cl.). In the medial part of the telencephalon there could be noted a fairly large cell mass. This cell mass forms the caudate nucleus, which began to resemble that of the adult state (Fig. 25 , N. Cau.). Just lateral to the caudate nucleus there could be observed a large rather oval cell mass, which forms the putamen. The putamen at this stage began to resemble that of the adult form (Fig. 25, pu.).

At a level caudal to the precommissural level there was seen ventral to the D2 am pallial zone, an early stage of the hippocampal cortex or Ammon's horn and the dentate fascia (Fg. 26, ah. and fd.). In form the Ammon's horn had begun to foreshadow its adult form. The pyramidal cells of the hippocampal cortex could be only vaguely demarcated, but at the lateral extremity of the hippocampus the pyramidal cells could be more definitely demarcated. At the lateral part of the dorsal extremity of the hippocampus there could be seen a scattering of its cells. Ventral to Ammon's horn there could be observed the dentate fascia. In the dentate fascia there could be noted the granule cells, which were closely arranged. However, these granule cells were as yet hoorly defined.

In the dorsolateral part of the telencephalon there could be seen the D2 al pallial zone. The D2 al zone showed in its telencephalic wall an ependymal and an inner mantle layer. The inner layer of the mantle zone was thinner than in the previously described stage. The outer or intermediate layer of the mantle zone had however become thicker. It contained some loosely arranged cells and numerous fibers. Peripheral to the mantle layer there could be noted the pyramidal layer, which was quite thick. Just internal to the pyramidal layer there was seen a more loosely arranged internal granular layer. At tne periphery of the pyramidal layer there was noted a thin compact external granular layer and an outer marginal layer (Fig. 26, D2 al). Ventral to the D2 al zone there could be noted the $\mathrm{D}(2+1) \mathrm{b}$ pallial zone. The $\mathrm{D}(2+1) \mathrm{b}$ zone resembled in point of development that of the D2 al zone (Fig. 26, D $(2+1) b$ ).

The $D(2+1)$ c zone began to resemble the pyriform cortex of the adult state (Fig. 26, P.L.). Just ventral to the $\mathrm{D}(2+1) \mathrm{c}$ pallial zone there could be noted the lateral olfactory tract, which began to resemble that of the adult state (Fig. 26 , tr. ol. It.). Ventromedially there could be seen the preoptic recess (Fig. 26, r. p. o.). Just lateral to it there could be seen the rostral extremity of the hypothalamus (Fig. 26, hy.). In the area of the ventromedial border of the telencephalon there could still be noted the sulcus telo-diencephalicus (Fig. 26, std.). Lateral to the sulcus telo-diencephalicus there could be observed, at the ventral border of the telencephalic wall, a cell mass consisting of closely arranged cells. This cell mass forms the transitional area lying between the tuberculum olfactorium and the periamygdalar cortex (Fig. 26, 
ar. trns. vls.).

In the dorsal part of the ventromedial area of the telencepholon there could be observed the caudal part of the B4 zone (Fig. 26, B4). Just ventral to the B4 basal zone, there could be seen the caudal part of the B3 zone (Fig. 26, B3). In the medial extremity of the ventromedial part of the telencephalic wall the diagonal band of Broca could be noted (Fg. 26, Bs. d.). The caudate nucleus had become considerably larger at this level. It began to resemble the caudate nucleus of the adult state (Fig. 26, N. Cau.). Just lateral to the internal capsule there could be observed a large, rather oval shaped cell mass of closely packed cells. This cell mass formed thee putamen. The putamen had begun to resemble that of the adult state (Fg. 26, pu.). Just lateral to the putamen there could be noted a thin band like group of closely packed cells. This cell mass forms the claustrum. It began to resemble the claustrum of the adult state (Fg. 26, Cl.).

At a level of the middle part of the anterior commissure the D2 am pallial zone could be noted. In the D2 am pallial zone there could be noted an outer compact layer of cells and an inner more loosely arranged layer of cells. Thus, the D2 am zone began to resemble that of the adult parahippocampal cortex state; but the cell layers were not as clearly demarcated as in the adult state (Fig. 27, Pah.Ct., Ph.E. and Ph.i.). Ventrolateral to the D2 am zone there could be seen the $\mathrm{D} 2$ al pallial zone, which resembled the D2 al zone at more rostral telencephalic levels (Fg. 27, D2 al). Ventrolateral to the D2 al zone, there could be seen the $\mathrm{D}(2+1) \mathrm{b}$ pallial zone (Fg. 27, D $(2+1)$ b). This pallial zone resembled the $D(2+1) b$ pallial zone of the more rostral telencephalic levels.

Just ventral to the $D(2+1) b$ zone, there could be noted the $\mathrm{D}(2+1) \mathrm{c}$ pallial zone, which began to resemble the adult pyriform cortex (Fg. 27, P. L.). At the ventral extremity of the $D(2+1)$ c zone there could be observed the lateral olfactory tract (Fig. 27, tr. ol.1t.). Just ventral to the lateral olfactory tract there could be seen a fairly thick band like cell group consisting of rather loosely arranged cells (Fig. 27, Bs. vlp.). This cell mass forms the periamygdalar cortex which began to resemble that of the adult state. Ventromedial to the periamygdalar cortex there was noted the sulcus telo-diencephalicus (Fg. 27, std.). Just ventromedial to this sulcus the preoptic level of the hypothalamus and the preoptic recess could be observed (Fig. 27, Hy. pr. and r. p. o.).

In the dorsomedial wall of the telencephalon ventral to the D2 am zone, there could be observed the cornu Ammonis (Fig. 27, ah.). The cornu Ammonis at this stage began to foreshadow that of the adult state. Thus, the pyramidal cell layer of the hippocampus showed a scattering of its cells at its lateral extremity. The pyramidal cells could only be vaguely demarkated in the hippocampal cortex, at this level. Just ventral to Ammon's horn the dental fascia could be noted (Fg. 27, fd.). The granule cells of the dentate fascia and the pyramidal cells of the Ammon's horn are derived from the primordial granular or cortical layer of early developmental stages of the D3 zone. In the ventromedial part of the telencephalon there could be seen the B3 basal zone (Fig. 27, B3). Just dorsal to the B3 basal zone there could be seen the B4 basal zone (Fig. 27, B4).

Lying just medial to the $\mathrm{D}(2+1) \mathrm{b}$ pallial zone there could be noted a thin band like group of closely packed cells. This cell mass forms the claustrum, which began to resemble that of the adult state (Fg. 27, Cl.). Just medial to the claustrum there could be noted a large cell mass consisting of closely packed 
cells. This cell mass forms the putamen, which began to resemble that of the adult state (Fig. 27, pu.). Just medial to the putamen there could be seen the caudate nucleus. The caudate nucleus likewise began to resemble that of the adult state (Fig. 27, N. Cau.). Just ventral to the putamen there could be seen a fairly large group of large and some small cells closely arranged. This cell mass forms the globus pallidus (Fig. 27, pal.). At this stage, the globus pallidus had now joined the neostriatal components, namely the caudate nucleus and putamen.

Just medial to the periamygdalar cortex there could be seen a large oval group of closely packed cells. This cell mass forms the nucleus amygdala (Fig. 27, nu. am.). However, at this stage the various component amygdalar nuclei had not as yet been differentiated. There could be seen in the medial part of the ventromedial area of the telencephalon the diagonal band of Broca (Fig. 27, Bs.d.). The internal capsule and the middle part of the anterior commissure could be noted at this level (Fig. 27, c. i. and c. a.).

\section{Trichosurus vulpecula, $44 \mathrm{~mm}$}

At the level of the anterior part of the precommissural level of the telencephalon, the D2 am pallial zone could be noted in the dorsomedial sector of the telencephalon. In the telencephalic wall of this pallial zone there could be seen an outer dense layer of closely packəd cells and an inner layer of more loosely arranged cells. Just peripheral to the outer dense layer, there could be noted a thin zonal or molecular layer. The D2 am zone gives rise to the parahippocampal cortex, which now resembled that of the adult state. Just ventral to the parahippocampal cortex there may be noted the precommissural hippocampus. The precommissural hippocampus was not differentiated into a separate Ammon's horn and a dentate fascia. It formed a single cell area which represents the fused Ammon's horn and dentate fascia cell areas. According to Kuhlenbeck (1960), a rudimentary precommissural hippocampal area is present in most of the placental mammals.

Ventrally a band like cell mass could be seen. This cell mass forms the tuberculum olfactorium; which resembled that of the adult state. In the ventromedial extremity of the telencephalon, the diagonal band of Broca could be seev. The caudate nucleus could be seen, and at this stage it resembled that of the adult state. Just lateral to the caudate nucleus, a large oval cell mass could be noted which formed the putamen. The putamen likewise resembled that of the adult state. Just lateral to the putamen, a thin band like cell group could be seen which formed the claustrum. It likewise resemled that of the adult state.

In the dorsomedial part of the telencephalon, at the level of the anterior commissure, there could be observed Ammon's horn which had begun to resemble that of the adult state (Fig. 28, ah.). Thus, the pyramidal cells of Ammon's horn could be demarcated. At the lateral extremity of the dorsal part of Ammon's horn, there could be noted a scattering of the cells of Ammon's horn. Just ventral to Ammon's horn there could be seen the dentate fascia (Fig. 28, fd.). The dentate fascia had begun to resemble that of the adult state. The granule cells could be noted in the dentate fascia. However, they were not as well defined as in the adult state. Just dorsal to Ammon's horn, there could be seen the parahippocampal cortex (Fig. 28, Pah. Ct.). The parahippocampal cortex resembled that of the adult state. Thus, an outer densely packed cell layer, and an inner layer consisting of more loosely arranged cells could be demarcated. A 
thin peripheral molecular or zonal layer could also be seen.

Just dorsolateral to the parahippocampal cortex there was seen the neocortex. The neocortex consisted of an inner ependymal layer; an inner mantle layer; with an outer intermediate part of the mantle layer, an internal granular layer of rather loosely arranged ceells; peripheral to which was a compact, well defined pyramidal layer. The pyramidal layer contained many pyramidal shaped cells. Lying just peripheral to the pyramidal there was seen a thin compact external granular layer; and a thin marginal zone (Fig. 28, 1, 2. i., 3, I. G., Pyr., E. G. and Neoct.). Just ventral to the zone of the neocortex there was seen the insular cortex (Fig. 28, Ins. Ct.). The insular cortex is a particular sub-region of the neocortex. It resembled in point of development that of the neocortex. It represents a region of cerebral cortex transition lying between the neocortex and the paleocortex. Ventral to the insular cortex there could be observed the pyriform cortex which resembled the pyriform cortex of the adult state (Fig. 28, P.L.). At this level the anterior part of the hypothalamus and tne optic chiasm could be noted (Fg. 28, hy. and Opt. Ch.). The anterior commissure was fully formed and could be noted at this level (Fg. 28, c. a.). At the ventromedial extremity of the telencephalon the sulcus telo-diencephalicus could still be seen (Fig. 28, std.).

The amygdala showed a considerable advance in its state of differentiation as compared with that stage previously described. The amygdala formed a rather oval shaped cell mass (Fg. 28, nu. am.). There could be demardated at this level of the telencephalon in the amygdala, a Gamma amygdalar nucleus and a Beta amygdalar nucleus (Fg. 28, nu.c. and nu. b.). In addition, there could be demar- cated the amygdalar nucleus alpha; which is derived from the periamygdalar cortex (Fg. 28, a.). At this stage it was a well differentiated cell mass. According to Kuhlenbeck (1924 and 1929) the Beta amygdalar nucleus is derived from a fusion of the caudal parts of the zones $\mathrm{D} 1+\mathrm{B} 1+\mathrm{B} 2$ and the Gamma amygdalar nucleus is also derived from the caudal parts of the zones $\mathrm{D} 1+\mathrm{B} 1+\mathrm{B} 2$. He also stated that the amygdalar nucleus alpha is derived from the periamygdalar cortex, which is derived from the zones $\mathrm{B} 1+\mathrm{B} 2$ +B3. The caudate nucleus at this stage resembled that of the adult state and the putamen likewise resembled that in the adult state (Fig. 28, N. Cau. and p. u.). The golbus pallidus aiso resembled that of the adult state (Fig. 28, pal.). Lateral to the putamen there could be noted the claustrum. It resembled that noted in the adult state (Fig. 28, Cl.).

At the level of the caudal part of the telencephalon, there could be observed in the dorsomedial wall of the telencephalon the Ammon's horn. There could be noted a scattering of the pyramidal cells at the lateral extremity of Ammon's horn (Fig. 29, ah.). At its lateral extremity and in most of the area of Ammon's horn there could be noted some pyramidal cells, which were not yet as well defined as in the adult state. However, the Ammon's horn foreshadowed that of the adult state. Just ventral to Ammon's horn there could be seen the dentate fascia. In the dentate fascia there could be noted numerous fairly well formed granule cells (Fg. 29, fd.). Just dorsal to Ammon's horn there could be seen the parahippocampal cortex (Fg. 29, Pah. Ct.). The parahippocampal cortex consisted of a thin peripheral molecular or zonal layer, and just below this layer, there could be noted an outer dense layer of cells (Fig. 29, Ph. E., and Zon.). Just below this layer there could be seen an inner loosely 
arranged cell layer (Fig. 29, Ph. i.).

Just below the neocortex there could be noted the $\mathrm{D}(2+1) \mathrm{b}$ pallial zone or the insular cortex (Fig. 29, Ins. Ct.). The insular cortex resembled that noted at the level of the anterior commissure. Just ventral to the insular cortex there could be noted the pyriform cortex (Fig. 29, P. L.). The pyrifom cortex resembled that of the adult state. Just below the hippocampus the hippocampal commissure could be noted (Fig. 29, C. hip.). It resembled the hippocampal commissure of the adult state.

The caudate nucleus could be noted at this level. It was practically fully formed, and resembled that of the adult state (Fig. 29, N. Cau.). The putamen likewise was fully formed and resembled that of the adult state (Fig. 29, pu.). Just lateral to the putamen the claustrum could be seen. It formed a thin compact band like cell group (Fig. 29, Cl.). Just ventromedial to the putamen, the globus pallidus could be noted. In form it resembled the globus pallidus of the adult state (Fig. 29, pal.). In the ventral part of the claustrum there could be noted a doubling of the claustrum. Thus there could be seen at this level of the claustrum, an outer part namely the claustrum externum, and an inner layer or part, namely the claustrum internum (Fig. 29, Cl. ext. and $\mathrm{Cl}$. int.). This doubling of the claustrum has also been noted by Kuhlenbeck (1974) in the adult rabbit. According to Kuhlenbeck (1974) the griseum representing the inner claustrum may be regarded as a transitional structure located between the outer or true claustrum and the main amygdaloid complex. Thus, this doubling of the claustrum is related to the fact that the claustrum arises from a common matrix with the nucleus amygdalae Beta. $\mathrm{He}$ further stated, that it is therefore arbitrary, whether this transitional cell group should be evaluated as pertaining to the claustrum or to the amygdaloid nuclear complex. The lateral or main part of the claustrum is derived from the lateral part of the epistriatum or the nucleus epibasalis anterior.

At this level of the forebrain there could be noted the anterior thalamic nuclei, namely the nucleus anterodorsalis thalami and the nucleus anteroventralis thalami (Fig. 29, N. ad. and N. av.). They resembled these thalamis nuclei of the adult state, and were almost fully formed. There could also be noted at this level the rostral part of the nucleus reticularis thalami (Fig. 29, N. Ret. R.). The anterior part of the hypothalamus could also be seen (Fig. 29, hy.). At this caudal level of the telencephalon there could be noted ventrally the Alpha amygdalar nucleus (Fig. 29, a.). The Alpha amygdalar nucleus had begun to resemble that of the adult state. The nucleus amygdalae Gamma was likewise almost fully formed (Fig. 29, nu. c.). It lies in the dorsal part of the amygdala. The nucleus amygdalae Delta could be noted at this level (Fig. 29, d. nu.). It lies in the ventromedial part of the amygdalar nucleus complex. It resembled in form that nucleus of the adult state. Lying above the Alpha amygdalar nucleus there could be noted the Beta amygdalar nucleus $(\mathrm{Fg} .29$, nu.b.). It is the main nucleus of the amygdalar nuclear complex. In form it resembled the Beta amygdalar nucleus of the adult state.

\section{Trichosurus vulpecula, $48 \mathrm{~mm}$}

At the precommissural level of the telencephalon in tne dorsomedial part of the telencephalic wall, there could be seen the parahippocampal cortex (Fig. 30, Pah. Ct.). At this stage the parahippocampal cortex resembled that of the adult state. It consisted of an outer fairly thick layer of densely packed cells and an inner cell layer, consisting of more loosely 
arranged cells (Fig. 30, Ph. E. and Ph. i.). There could also be noted a thin peripheral zonal or molecular layer (Fig. 30, Zon.). Just ventral to the parahippocompal cortex there could be noted at this level the precommissural hippocampus. At this level the precommissural hippocampus was not differentiated into a separate Ammon's horn and a dentate fascia. However it formed a single cell area, which constituted the fused area hippocampi and the dentate fascia; ane thus formed a single cell zone, namely the zones (ah.+fd.), (Fig. 30, prec. hipp.).

Just lateral to the parahippocampal cortex there could be seen the neocortical pallial zone. The neocortical zone consisted of an inner ependymal layer, an inner mantle layer, and an outer intermediate zone of the mantle layer (Fig. $30,1,2$. i. and 3). Peripheral to this layer was noted a well defined internal granular layer consisting of rather loosely arranged cells (Fig. 30, I. G.). Peripheral th this layer there was noted a well defined pyramidal layer, as well as a well defined compact external granular layer, and an outer marginal layer. The pyramidal layer, the internal granular layer, and the external granular were better defined than at the previously described stage (Fg. 30, Pyr., I. G. and M.G.). The pyramidal layer can be regarded as the beginning of what becomes the pyramidal stratum of the adult stage, according to Tilney and Kubie (1931).

Just ventral to the neocortical zone there could be seen the pyriform cortex. It formed a group of cells, which resembled that of the adult state (Fig. 30 , P.L.). At the ventral and ventrolateral extremity of the telencephlon, there could be seen a band like cell group, which formed the tuberculum olfactorium (Fg. 30, Bs. vla.). It resembled the tuberculum olfactorium of the adult state. In tne periphery of the ventromedial part of tne telencephalic wall there could be noted the diagonal band of Broca (Fig. 30 , Bs. d.). The caudate nucleus resembled that of the adult state. Just ventrolateral to the caudate nucleus there could be observed the putamen (Fig. 30, N. Cau. and pu.). At this stage the putamen also resembled that of the adult state. Just lateral to the putamen there could be noted a thin band like group of closely packed cells, which formed the claustrum (Fig. 30, Cl.).

At the precommissural level of the telencephalon there could be noted in the dorsomedial part of the ventromedial part of the telencephalon the nucleus basimedialis superior or septal nuclei of Kuhlenbeck (1969) and other authors. The nucleus basimedialis superior resembled that of the adult state (Fig. 30, Nu. Basm. S.). Ventral to this nucleus there was noted the nucleus basimedialis inferior, which likewise was almost fully formed and resembled that noted in the adult state (Fig. 30, Nu. Basm. in.).

At the level of the anterior commissure, in the dorsomedial part of the telencephalic wall there could be noted the Ammon's horn, which resembled that of the adult state (Fig. 31, ah.). The Ammons horn consisted largely of large pyramidal cells as well as a few small polymorphic cells. Just ventral to Ammon's horn there could be noted the dentate fascia (Fig. 31, fd.). The granule cells of the dentate fascia were almost fully formed. Jnst dorsal to Ammon's horn there could be seen the parahippocampal pallial zone. The parahippocampal cortex resembled that of the adult state (Fg. 31, Pah. Ct.). There could be observed an outer layer consisting of closely packed cells. Just below this cell layer there could be seen an inner layer consisting of more loosely arranged cells. In the periphery of the parahippocampal cortex there could be seen a thin zonal or molecular layer. 
Jnst dorsolateral to the parahippocampal cortex there could be noted the neocortical pallial zone. The neocortex resembled in point of development that noted at the precommissural level of the telencephalon (Fig. 31, Neoct.). It foreshadowed that of the adult state. Just below the neocortical zone, there could be seen the insular cortex, which foreshadowed that of the adult state (Fig. 31, Ins. Ct.). Just below the insular cortex there could be seen the pyriform cortex, which also resembled that of the adult state (Fig. 31, P. L.). At this level there could be noted in the pyriform ortex an outer fairly wide zonal or molecular layer; and there could be vaguely demarcated an outer densely arranged cell layer and an inner more loosely arlanged cell layer (Fig. 31, Zon.P.). The anterior commissure and the internal capsule were fully formed (Fig. 31, c.a. and c.i.). The caudate nucleus was fully formed and resembled that of the adult state (Fg. 31, N. Cau.). The putamen was likewise fully formed and resembled that of the adult state (Fig. 31 , pu.). The globus pallidus likewise resembled that of the adult state and was fully formed (Fig. 31, pal.). The optic chiasm and the rostral extremity of the hypothlamus could be noted at this level (Fig. 31, Opt. ch.).

At the level of the anterior commissure, the amygdala showed an advance in the degree of differentiation of its nuclei (Fig. 31, nu. am.). Thus, there could be noted at the peripheral part of the ventrolateral extremity of the telencephalon, the amygdalar nucleus Alpha (Fig. 31, a.). Lying just above the amygdalar nucleus Alpha, there could be seen the rostral part of the amygdalar nucleus Beta (Fig. 31 , nu. b.). Both of these amygdalar nuclei were fully formed and resembled those of the adult state. Just dorsal to the amygdalar nucleus Beta there was observed the rostral level of the amygdalar nucleus Gamma. This nucleus likewise resembled that of the adult state (Fig. 31, nu.c.). At the ventromedial border of the telencephalon there could still be noted the sulcus telo-diencephalicus (Fig. 31 , std.). Just ventrolateral to the putamen there could be noted the claustrum (Fig. $31, \mathrm{Cl}$.). It formed a thin band like cell group of closely arranged cells. In the ventral part of the dorsomedial zone of the telencephalon, there could be noted the caudal part of the B3 and B4 telencephalic zones (Fig. 31, B3 and B4).

In the $48 \mathrm{~mm}$ Trichosurus vulpecula embryo at the caudal level of the telencephalon, there could be noted the Ammon's horn of the hippocampal cortex (Fg. 32, ah.). The Ammon's horn consisted of a large number of almost fully formed pyramidal cells and a small number of smaller polymorphic cells. Just ventral to the Ammon's horn there could be noted the dentate fascia (Fig. 32, fd.). The dentate fascia consisted of almost fully formed granule cells. Both the Ammon's horn and the dentate fascia almost resembled that noted in the adult state. Dorsolateral to the hippocampus there could be seen the parahippocampal cortex. The parahippocampal cortex resembled that present in the adult state (Fig. 32, Pah. Ct.). It consisted of an outer densely packed layer of cells; and an inner thicker cell layer consisting of more loosely arranged cells. At the periphery of the outer dense cell layer, there could be demarcated a thin zonal or molecular layer (Fig. 32, Ph. E., Ph. i., and Zon.).

Dorsolateral to the parahippocampal cortex there could be seen the neocortex. The neocortex at this level resembled in point of development that noted in the more rostral levels of the telencephalon (Fig. 32, Neoct.). Just ventral to the neocortex there could be seen the pyriform cortex which resembled that noted at the level of the anterior com- 
missure (Fg. 32, P. L.). The caudate nucleus was fully formed and resembled that nucleus of the adult state (Fig. 32, N. Cau.). Just ventral to the caudate nucleus there could be seen the putamen (Fig. 32, pu.). The putamen was likewise fully formed, and was similar to that noted in the adult state.

Slightly medial to the putamen there could be observed the globus pallidus. The globus pallidus also resembled in form, that noted in the adult state (Fig. 32, pal.). At this level the middle level of the hypothalamus could also be seen. In the hypothalamus the dorsomedial and ventromedial hypothalamic nnclei could be demarcated (Fig. 32, hy., N.hdm. and N. hvm.). At the ventrolateral extremity of the hypothalamus there could be noted the nucleus tuberis hypothalami (Fig. 32, N. tub. hy.). Dorsal to the hypothalamus there could be noted the rostral extremity of the thalamus. Dorsal to the hypothamus there could be seen the nucleus anteroventralis of the thalamus (Fig. 32, N. av.). Just ventral and slightly lateral to the anterior thalamic nuclei there could be seen the rostral extremity of the nucleus reticularis thalami (Fig. 32, N. Ret. R.).

Lying ventromedial to the pyriform cortex there could be seen the amygdala. In the amygdala all the amygdalar nuclei of the adult state could be definitely demarcated. According to Kuhlenbeck (1924), the Alpha amygdalar nucleus was derived from the periamygdalar cortex (Fig. 32, a.). Kuhlenbeck (1924) also stated that the remaining amygdalar nuclei, namely the Beta, Gamma, and Delta amygdalar nuclei were all derived from the caudal extremities of the telencephalic zones D1, B1, and B2. The Alpha amygdalar nucleus resembled that of the adult state. Just dorsal to this nucleus there could be noted tho Beta amygdalar nucleus (Fig. 32, nu. b.). It forms the largest cell mass of the amygdalar group of nuclei. Just dorsomedial to the Beta amygdalar nucleus there could be noted the nucleus amygdalar Gamma (Fig. 32, nu.c.). The Gamma amygdalar nucleus also resembled that of the adult state.

In the ventromedial part of the telencephalon a small oval shape of cell mass could be noted, which formed the nucleus amygdalae Delta. This nucleus was likewise fully formed and resembled that nucleus of the adult state (Fig. 32, d. nu.). Just lateral to the putamen there could be seen a thin bandlike group of closely packed cells. This cell mass forms the matrix of the claustrum (Fig. 32, matr. cl.). Lying just ventral to the dorsal part of the matrix of the claustrum there could be noted a doubling of the claustrum; which consisted of an outer and an inner part. According to Kuhlenbeck (1974), the outer part of the claustrum constitutes the outer or true claustrum. $\mathrm{He}$ also indicated that this doubling of the claustrum is related to the fact that the claustrum takes origin from a common matrix with the nucleus amygdalae Beta. According to Kuhlenbeck (1974), he has indicated that it was probable that a double claustrum was probably present in the adult Trichosurus vulpecula; and he noted a double claustrum in the rabbit and also in the adult marsupial Dromiciops australis.

\section{Discussion}

In the $7.25 \mathrm{~mm}$ stage of Trichosurus vulpecula there could be seen the typical general vertebrate pattern of the telencephalic longitudinal zones. These telencephalic zones which could be demarcated, were the pallial zones D1, D2, and the basal longitudinal zones of $\mathrm{B} 1$ and B2. There could also be noted the basal zone B3. In the $8.5 \mathrm{~mm}$ Trichosurus vulpecula there could be seen the pallial zones D1, D2, and D3. There was noted 
some thickening of the telencephalic wall in the zone D1 and the fused zones of $\mathrm{B} 1+\mathrm{B} 2$. The sulcus telencephalo-diencephalicus and the velum transversum could be seen at this stage.

In the $10 \mathrm{~mm}$ stage of Trichosurus vulpecula there could be noted at the inner margin of the forebrain wall the torus hemisphaericus, which could be noted at the telo-diencephalic border zone. The pallial zones D1, D2, and D3 were now quite well defined. In the $11.5 \mathrm{~mm}$ Trichosurus vulpecula the basal zones $B 1$, $\mathrm{B} 2, \mathrm{~B} 3$, and B4 were quite well defined at this stage. The pallial telencephalic zones D1, D2, and D3 were also well defined. The sulcus fd 2 wyich demarcates the pallial zones D1 and D2, could be noted in the ventricular wall.

In the medial telencephalic wall there could be readily demarcated the $\mathrm{B} 3$ and the B4 basal telencephalic zones. The telencephalon at the $11.5 \mathrm{~mm}$ stage resembled that of the embryo of Tropidonotus natrix, as noted by Kuhlenbeck (1938). In the $16 \mathrm{~mm}$ Perameles nasuta the D2 pallial zone had split up; and had given rise to the $\mathrm{D} 2$ am zone, the $\mathrm{D} 2$ al zone, and the $\mathrm{D}(2+1) \mathrm{c}$ zone. In the $\mathrm{D} 2$ al zone there was noted a considerable thickening of the telencephalic wall. In reptiles the primordium neopallii is an early development of the D2 al zone. According to Kuhlenbeck (1924 and 1929) the $\mathrm{D} 2+1$ pallial zone is formed from the lateral part of the zones D2 and D1. According to Kuhlenbeck (1924 and 1929). the D2 am telencephalic zone is the matrix from which the parahippocampal zone is derived and the D3 zone is the anlage of the futurehippocampal formation. It shows no evidence of any special differentiation as yet. In the $19 \mathrm{~mm}$ Trichosurus vulpecula the D2 am zone, the D2 al zone, the $\mathrm{D}(2+1) \mathrm{c}$ zone, and the $\mathrm{D} 3$ pallial zone could be definitely observed.

In the $19 \mathrm{~mm}$ Trichosurus vulpecula, there was noted in the medial wall of the telencephalon the $\mathrm{B} 3$ and $\mathrm{B} 4$ basal zones. The basal telencephalic B1 zone had become greatly thickened and protruded into the ventricle. At a caudal telencephalic level the basal telencephalic zones $\mathrm{B} 2$ and $\mathrm{B} 3$ could be noted. At this stage there could be seen the $D(2+1) C$ pallial zone, which aeeording to Kuhlenbeck (1924) later gives rise to the pyriform cortex. As yet, no evidence of any special differentiation could be seen in the D3 pallial zone. The primordium or forerunner of the periamygdalar cortex could also be seen. According to Kuhlenbeck (1924 and 1929) the periamygdalar cortex is derived from the basal zones $\mathrm{B} 1+\mathrm{B} 2+\mathrm{B} 3$.

In the $24 \mathrm{~mm}$ Trichosurus vulpecula the D2 am pallial zone consisted of an ependymal layer, an inner mantle layer, an outer intermediate layer, and an outer primordial granular or cortical layer as well as a thin marginal zone. This stage of cortical development is comparable to the four layered stage of cortical development, noted by Tilney and Kubie (1931) in the $13 \mathrm{~mm}$ cat embryo. Kuhlenbeck and Domarus (1921) have also shown a four cell layer stage in Lacerta agilis; which is comparable to the four layered stage in the cerebral cortex of the 24 $\mathrm{mm}$ Trichosurus vulpecula. According to Tilney and Kubie (1931) the condions at this stage point to the recapitulation of the reptilian conditions inthe mammalian brain.

At the $24 \mathrm{~mm}$ stage of Trichosurus vulpecula, there could be definitely demarcated the palleal $D(2+1) b$ zone. According to Kuhlenbeck (1924 and 1929), the $\mathrm{D}(2+1) \mathrm{b}$ zone is the forerunner of the future insular cortex. In the D3 pallial zone no special degree of cortical differentiation could as yet be noted. The primordium of the future tuberculum olfactorium could be noted at the ventrolateral border of the telencephalon. The 
basal telencephalic zones B3 and B4 could be readily demarcated. These findings in the early stages of Trichosurus vulpecula embryos resemble these of Kuhlenbeck (1924, 1929 and 1938), in amphibians, reptiles, and birds in both embryonic and adult forms.

In the $16 \mathrm{~mm}$ Perameles nasuta and the $19 \mathrm{~mm}$ Trichosurus vulpecula stages the D2 pallial zone had already definitely split into the D2 am pallial zone, the D2 al pallial zone, and the $\mathrm{D}(2+1) \mathrm{c}$ pallial zone. The praepiriform cortex forms the pallial zone $\mathrm{D}(2+1) \mathrm{c}+\mathrm{B} 1$. It could be first demarcated at the $30 \mathrm{~mm}$ stage of Trichosurus vulpecula. According to Kuhlenbeck (1924 and 1929) the praepiriform cortex is derived from the $D(2+1) c$ pallial area.

In Trichosurus vulpecula the D2 am pallial zone gives ries to the parahippocampal cortex; aed the D2 al zone gives rise to the neocortex. According to Tilney and Kubie (1931), they noted in the neocortex of the cat that the primordial granular or cortical layer gave rise to the pyramidal layer, an internal granular layer, and an external granular layer. In Trichosurus Vulpecula there could be similarly noted in the neocortex of the $44 \mathrm{~mm}$ and $48 \mathrm{~mm}$ srages Trichosurus vulpecula a well defined pyramidal layer, an internal granular layer, and an external granular layer. Thus, the findings in Trichosurus vulpecula resemble those of Triney and Kubie (1931) in the cat. The manner of development of the neocortex in Trichosurus vulpecula is similar to that noted by Tilney and Kubie (1931) in the cat. According to Tilney and Kubie (1931) the pyramidal layer in the developing neocortex can be regarded as the beginning of what becomes the pyramidal stratum of the adult stage.

In Trichosurus volpecula the $\mathrm{D}(2+1) \mathrm{b}$ pa-lial zone gives rise to the insular cortex. According to Kuylenbeck (1924 and 1929) the $\mathrm{D}(2+1) \mathrm{b}$ pallial zone is derived from the baso-lateral extremity of the D2 al pallial zone, and also from the $\mathrm{D} 1$ pallial zone. Tho $\mathrm{D}(2+1) \mathrm{b}$ pallial zone is a sub-region of the neocortex. The $D(2+1) c$ pallial zone gives rise to the pyriform cortex. An early stage of development of the dentate fascia and an Ammon's horn were noted in the $41 \mathrm{~mm}$ stage of Trichosurus vulpecula. The dentate fascia and Ammon's horn were both well defined structures at the 44 and $48 \mathrm{~mm}$ stages of Trichosurus vulpecula. A precommissural rudimentary hippocampus could be noted at the $41 \mathrm{~mm}, 44$ $\mathrm{mm}$, and the $48 \mathrm{~mm}$ stages of Trichosurus vulpecula A precommissural rudimentary hippocampus has been similary noted in the adult rabbit by Kuhlenbeck (1960).

The findings as to the origin and differentiation of the D2 am, D2 al, and $D(2+1) c$ pallial areas in Trichosurus vulpecula are similar to those of Kuhlenbeck (1922, 1924, 1929 and 1938) in amphibia, reptiles, birds and mammals. The D3 pallial zone in Trichosurus vulpecula gives rise to the hippocampus. This was similarly noted in reptiles, birds, Marsupials, and mammals by Kuhlenbeck (1924, 1929 and 1938). According to Kuhlenbeck (1922, 1924, 1925 and 1929), the hypopallial ridge in reptiles is derived from the joined zones of D1, B1' and B2. In mammals the hypopallial ridge consists of an anterior part, which forms in mammals the nucleus epibasalis anterior, and a posterior part, which forms the nucleus epibasalis posterior. This nucleus is equivalent to the nucleus sphaericus of Edinger. The nucleus epibasalis posterior becomes in mammals a component of the amygdaloid nuclear complex.

The claustrum in Trichosurus vulpecula was derived from the lateral part of the nucleus epibasalis anterior. A doubling the claustrum consisting of an outer and an inner part was noted in Trichosurus 
vulpecula. It is derived from the pallial zone D1 and the basal zones B1 and B2. According to Kuhlenbeck (1974), in marsupials such as Dromiciops australis there is to be noted a double claustrum. $\mathrm{He}$ indicated that a double claustrum was probably present in the adult Trichosurus vulpecula. Kuhlenbeck (1974) also has noted a double claustrum in the adult rabbit. This resembles the findings of Kuhlenbeck (1924, 1925, 1929, and 1974) in marsupials and mammals. The caudate nucleus and the putamen were both derived from the medial part of the nucleus epibasalis anterior or epistriatum in Trichosurus vulpecula. The nucleus epibasalis anterior is equivalent to the neostriatum of Kappers (1921). Thus, they are both derived from the zones D1, $\mathrm{B} 1$, and B2. This is similar to the findings of Kuhlenbeck (1924, 1925, and 1929) in marsupials and mammals.

The globus pallidus originated in Trichosurus vulpecula from a primordium in the dorsolateral part of the hypothalamic zone. According to Kuhlenbeck (1924, 1925, and 1929) it is a differentiation of the anterior entopeduncular nucleus. In Trichosurus vulpecula the anlage of the globus pallidus appeared at the $30 \mathrm{~mm}$ stage. The anlage of the globus pallidus migrated rostrally, and at the $40 \mathrm{~mm}$ Trichosurus vulpecula stage it had joined the putamen and caudate nucleus to become the mammalian form of the globus pallidus. Kuhlenbeck (1924, 1925, and 1929) has similarly noted a similar origin and development of the globus pallidus in marsupials and mammals. In Trichosurus vulpecula the periamygdalar cortex becomes the adult amygdalar nucleus $\mathrm{A}$. According to Kuhlenbeck (1924 and 1929) the amygdalar nucleus $A$ is derived from the basal zones B1, B2, and B3; and the other amygdalar nuclei, namely the Gamma, Delta, and Beta amygdalar nuclei are derived in marsupials and mammals from the caudal parts of the zones (D1+B1+ B2).

In Trichosurus vulpecula similarly, the amygdalar nucleus $A$ is derived from the basal zones B1, B2, and B3; and the other amygdalar nuclei namely, the Gamma, Beta, and Delta amygdalar nuclei were derived from the caudal parts of the zones (D1+B1 +B2). According to Kuhlenbeck (1969), the B4 basal zone gives rise to the nucleus basimedialis superior, which later forms the septal nuclei. The B3 basal zone gives rise to the nucleus basimedialis inferior. According to Kuhlenbeck (1969), the nucleus basimedialis inferior gives rise to the bed nuclei of the anterior commissure, as well as of the stria terminalis, and the nucleus accumbens of Kuhlenbeck (1924).

\section{References}

1) Frederikse, A.: The brain of the lizard (Lacerta vivipara). Dissertation, Amsterdam, 1931.

2) Gronberg, G.: Die Ontogenese eines neidern Saugergehirns nach Untersuchungen an Erinaceus europaeus. Zool. Jahrb., Abt. f. Anat., Bd. 15, S. 261, 1901.

3) Kappers, Ariens, C.U.: Weitere Mitteilungen uber die Phylogenese des Corpus triatum und des thalamus. Anat. Anz., Bd. 33, S. 321, 1908.

4) Kappers, Ariens, C.U.: The phylogenesis of the paleo-cortex and archicortex compared with the evolution of the visual neocortex. Arch. Neurol., (Motts), Vol. 4, p. 161, 1909.

5) Kappers, Ariens, C.U.: The ontogenetic development of the corpus striatum in birds and a comparison with mammals and man. Proc. Kon. Akad. Wetens., Amsterdam, vol. 26, pp. 135-158, 1922.

6) Kuhlenbeck, H.: Ueber den Ursprung der Grosshirnrinde. Anat. Anz., Bd. 55, S. $337,1922$.

7) Kuhlenbeck, H.: Ueber den Ursprung der Basalganglien des Grosshirns. Anat. Anz., Bd. 58, S. 49, 1924. 
8) Kuhlenbeck, H. . Ueber die Homologien der Zellmassen im Hemispharenhirn der Wirbeltiere. Folia Anat. Japon, vol. 2, pp. 325-365, 1924.

9) Kuhlenbeck, H.: Weitere Mitteillungen zur Genese der Basalganglien. Anat. Anz., Bd. 60, S. 33, 1925.

10) Kuhlenbeck, H.: Betrachtungen über den funktionellen Bauplan des Zentralnervensystems. Folia Anat. Japon, vol. 2, p. 325, 1926.

11) Kuhlenbeck, H.: Die Grundbestandteile des Endhirns im Lichte der Bauplanlehre. Anat. Anz., 67, S. 1, 1929.

12) Kuhlenbeck, H.: The ontogenetic development and phylogenetic significance of the cortex telencephali in the chick. J. Comp. Neur., vol. 69, pp. 273-301, 1938.

13) Kuhlenbeck, H.: A note on the cortex telencephali of the marsupial Dromiciops australis. Anat. Rec. vol. 133; p. 401, 1959.

14) Kuhlenbeck, H.: Some comments on the development of the human corpus callosum and septum pellucidum Acta Anat. Nippon., 44, pp. 245-256, 1969.

15) Kuhlenbeck, H.: Doubling of the clau- strum in the marsupial Dromiciops australis and in the rabbit. (Personal communication, 1974), 1974.

16) Kuhlenbeck, H. and E.V. Domarus: Zur Ontogenese des menschlichen Grosshirns. Anat. Anz., 53, pp. 316-320, 1920.

17) Kuhlenbeck, H., E.C. Szekely, and H. Spuler: Some remarks on the zonal pattern of mammalian cortex cerebri as manifested in the rabbit. Confin. neurol., 20, pp. 407-423, 1960.

18) Landau, E.: The comparative anatomy of the nucleus amygdalae, the claustrum and the insular cortex. J. Anat., vol. 53, pp. 351-360, 1919.

19) Smith, G. Elliot: A preliminary note on the morphology of the corpus striatum and the origin of the neopallium. J. Anat., vol. 53, pp. 271-291, 1919.

20) Tilney, F. and L.S. Kubie: Behavior in its relation to the development of the brain. Bull. Neur. Inst. N.Y., vol. 1, pp. 229-313, 1931.

21) Warner, F.J.: The development of the forebrain of the American water snake (Natrix sipedon). J. Comp. Neur., vol. 84, no. 3, pp. 385-418, 1946.

\section{Explanation of Figures}

\section{Abbreviations}

a. Amygdalar nucleus Alpha

ah. Ammon's horn

am. pr. Primordium of the amygdaloid nuclear complex

ar. trns. vls. Transitional area between the tuberculum olfactorium and the periamygdalar cortex

ar. trns. vls. pr. Primordium of the transitional area between the tuberculum olfactorium and the periamygdalar cotex

B1 Basal zone B1

B2 Basal zone B2

B3 Basal zone B3

B4 Basal zone B4

$\mathrm{B} 1+\mathrm{B} 2$ Fused basal zones $\mathrm{B} 1$ and $\mathrm{B} 2$

Bs. d. Diagonal band of Broca

Bs. vla. Tuberculum olfactorium

Bs. vla. pr. Primordium of the tuberculum olfactorium
Bs. vlp. Periamygdalar cortex

Bs. vlp. pr. Primordium of the periamygdalar cortex

C. hip. Commissura hippocampi

c.a. Anterior commissure

c.i. Internal capsule

Cl. Claustrum

Cl. ext. External lamina of the claustrum

Cl. int. Internal lamina of the claustrum

D1 Pallial zone D1

D2 Pallial zone D2

D3 Pallial zone D3

D2 al Pallial zone D2 al

D2 am Pallial zone D2 am

$\mathrm{D} 2+1$ Pallial zone D2 +1

$\mathrm{D}(2+1) \mathrm{b} \quad \mathrm{D}(2+1) \mathrm{b}$ Pallial zone

$\mathrm{D}(2+1) \mathrm{c}$ Pallial zone $\mathrm{D}(2+1) \mathrm{c}$

$\mathrm{D}(2+1) \mathrm{c}+\mathrm{B1}$ Praepiriform cortex

d. nu. Amygdalar nucleus Delta 
E.G. External granular layer

Ep. Ependymal layer

et. Epithalamus

Ev. Op. St. Evagination of optic stalk

fd. Dentate fascia

fd. 1 Fissura dorsalis 1 , demarcates the pallial zone D1 from the basal zone B1

fd. 2 Fissura dorsalis 2, demarcates the Pallial zone D1 from the pallial zone D2

fd. 4 Fissura dorsalis 4, demarcates the pallial zone D3 from the basal zone B4

F.M. Foramen of Monro

Hp. Hippocampus

hy. Hypothalamus

Hy. pr. Pars preoptic of the hypothalamus

I.G. Internal granular layer

inf. Infundibulum

Ins. Ct. Insular cortex

1. af. Lamina affixa

matr. cl. Matrix of claustrum

M.G. Marginal layer

M1. Mantle cell layer

N. ad. Nucleus anterodorsalis thalami

N. av. Nucleus anteroventralis thalami

N. Cau. Caudate nucleus

1 Ependymal layer

2 Mantle cell layer

2.i. Inner portion of mantle cell layer

3 Intermediate outer part of mantle layer

N. hdm. Dorsomedial nucleus of the hypothalamus

N. hvm. Ventromedial nucleus of the hypothalamus

N. Ret.R. Rostral part of nucleus reticularis thalami

N. tub. hy. Nucleus tuberis of hypothalamus

Neoct. Neocortex

nu. am. Nucleus amygdalae

nu. b. Amygdalar nucleus Beta

Nu. Basm. in. Nucleus basimedialis inferior

Nu. Basm. S. Nucleus basimedialis superior nu. c. Amygdalar nucleus Gamma

Opt. ch. Optic chiasma

P.G. Primordial granular or cortical layer

P.L. Pyriform cortex

pa. Paraphysis

Pah. Ct. Parahippocampal cortex

pal. Globus pallidus

pal. pr. Primordium of globus pallidus

Par. Parencephalon

$\mathrm{Ph}$. E. Outer subdivision of parahippocampal cortex

Ph. i. Inner subdivision of parahippocampal cortex

Pr. ah. Primordium of Ammon's horn

Pr. fd. Primordium of dentate fascia

prec. hipp. Precommissural hippocampus

pu. Putamen

Pyr. Pyramidal layer

r.p.o. Preoptic recess

s.d. Sulcus dorsalis

Si. Sulcus intraencephalicus anterior

s.i.a. Sulcus lateralis infundibuli

s.m. Sulcus medius

S.R.I. Rhinal fissure

s. term. Sulcus terminalis

s.v. Sulcus ventralis

So.n. Supraoptic nucleus of hypothalamus

std. Sulcus telo-diencephalicus

t.d. Dorsal thalamus

t.h. Torus hemisphaericus

t.t. Torus transversus

t.v. Ventral thalamus

tel. rf. pl. Telencephalic roof plate

th. Thalamic zone

tr. ol. It. Lateral olfactory tract

v.t. Velum transversum

v. th. Ventral thalamus

Zon. Zonal or molecular layer of parahippocampal cortex

Zon. P. Zonal or molecular layer of pyriform cortex 


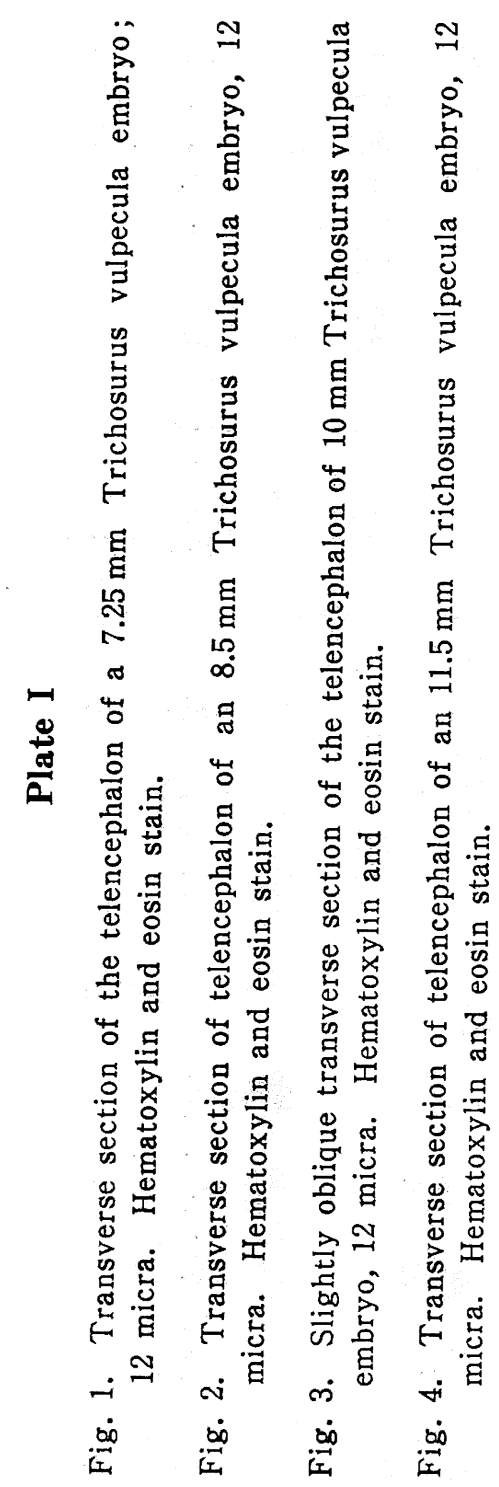



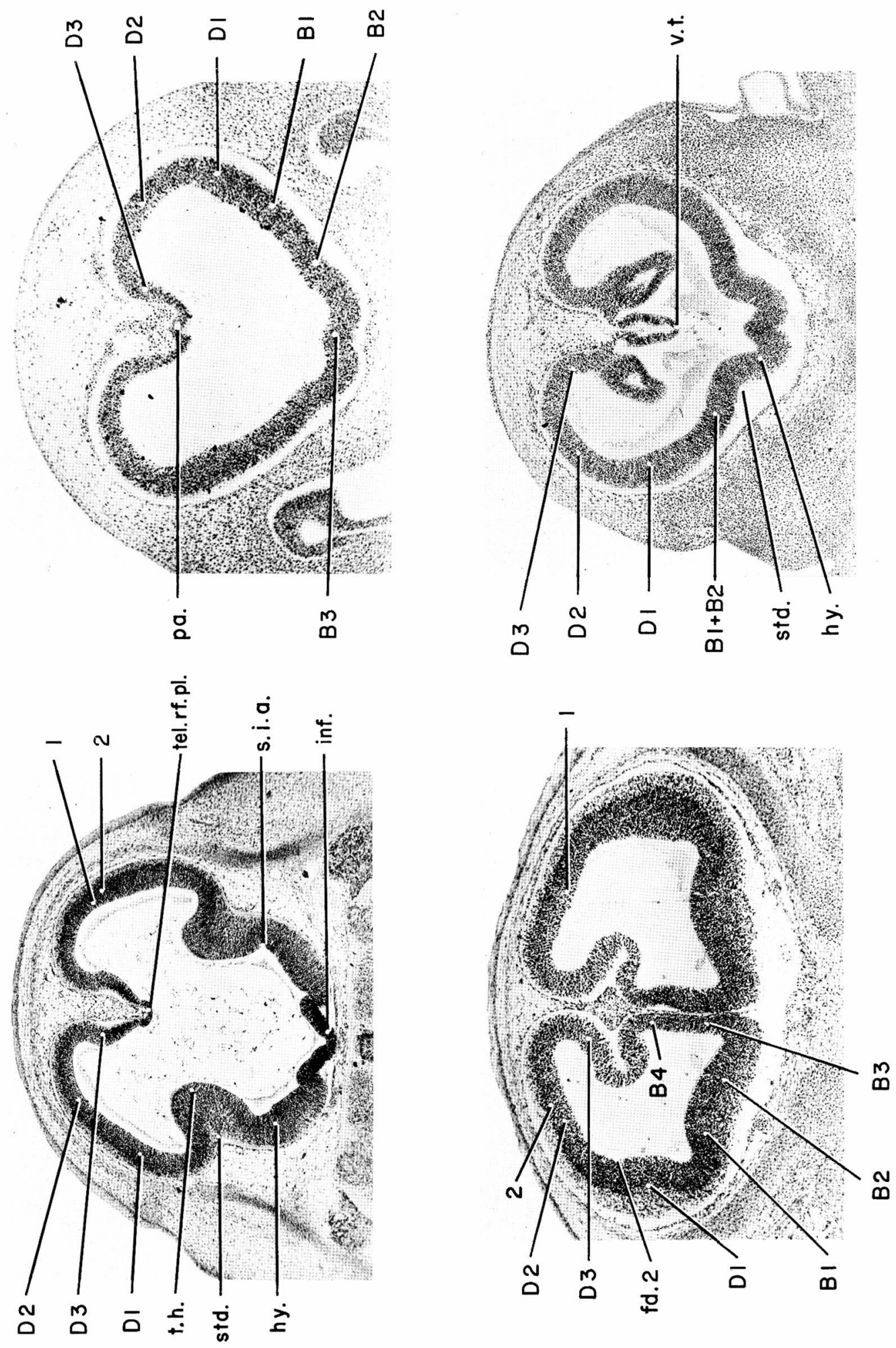


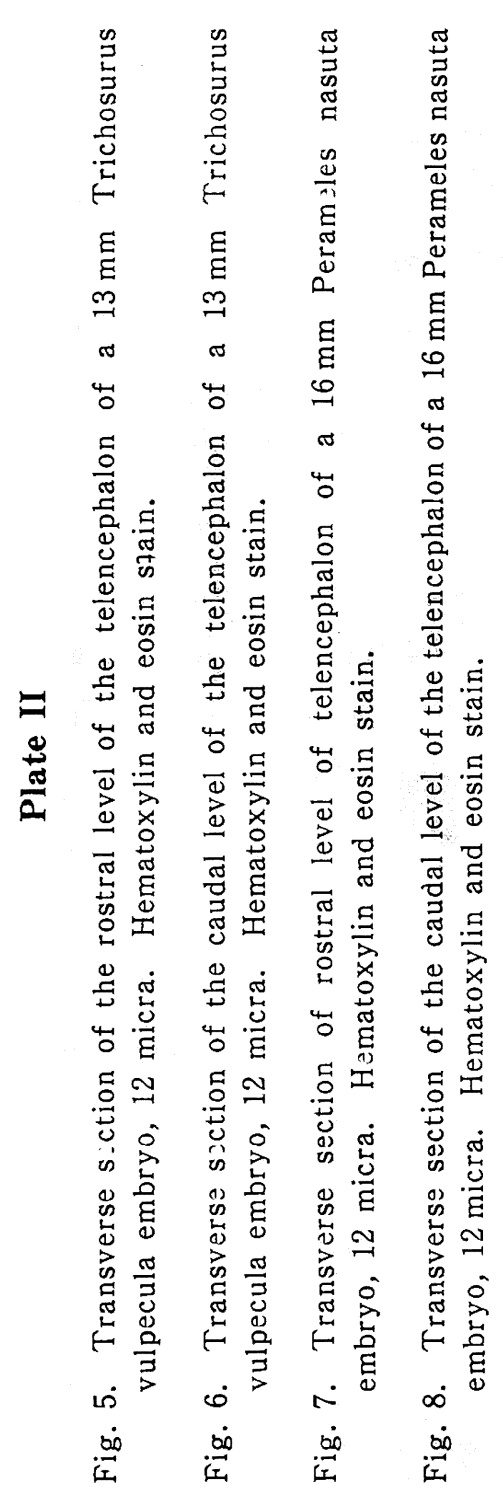


Plate II
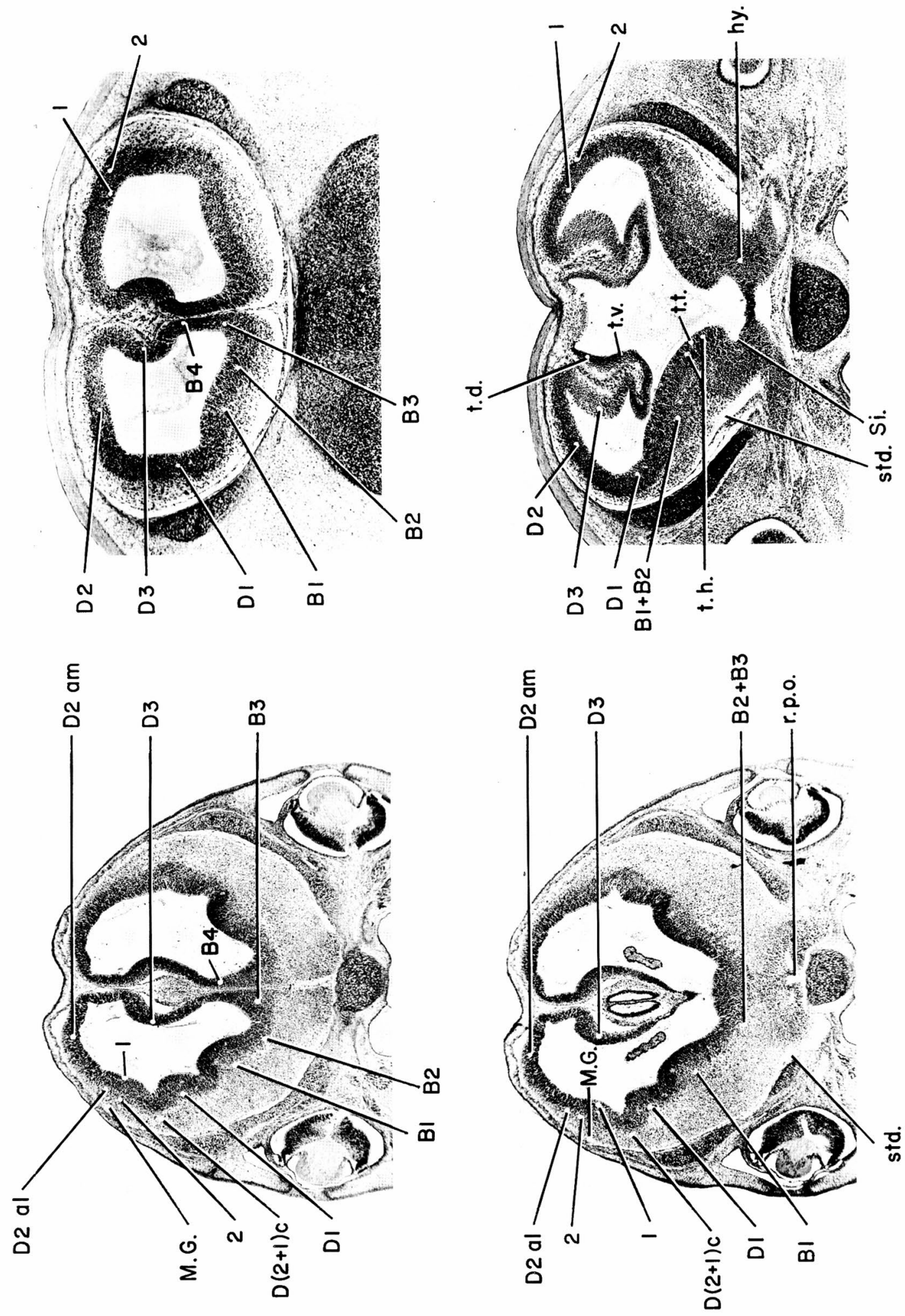


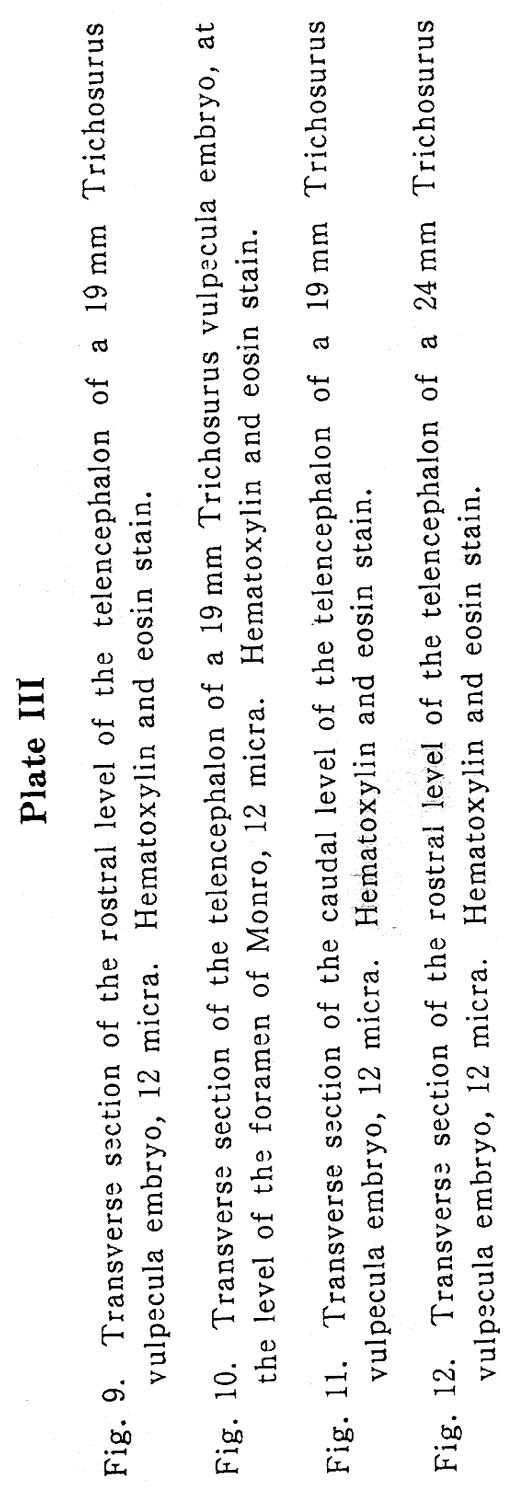


Plate III
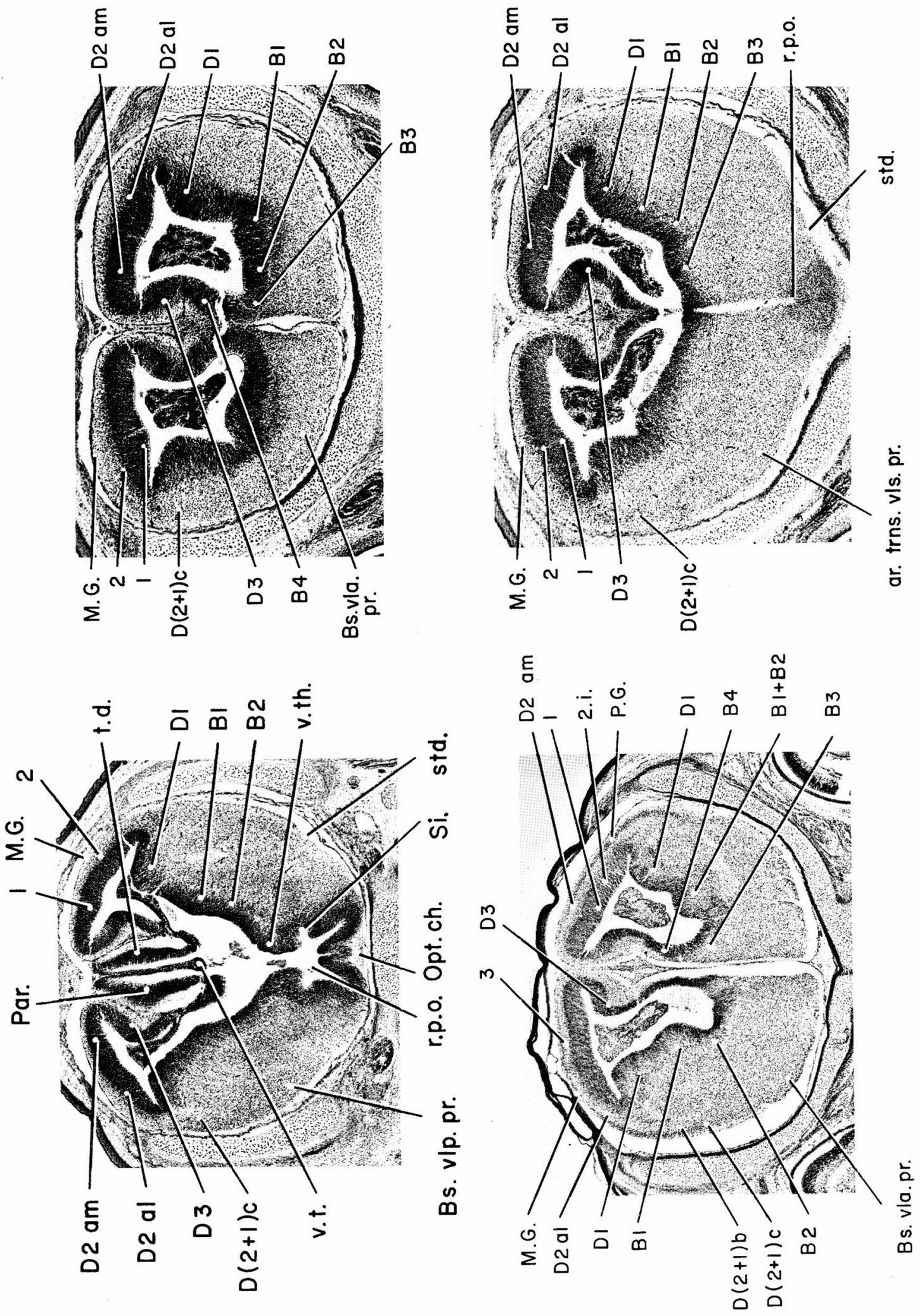


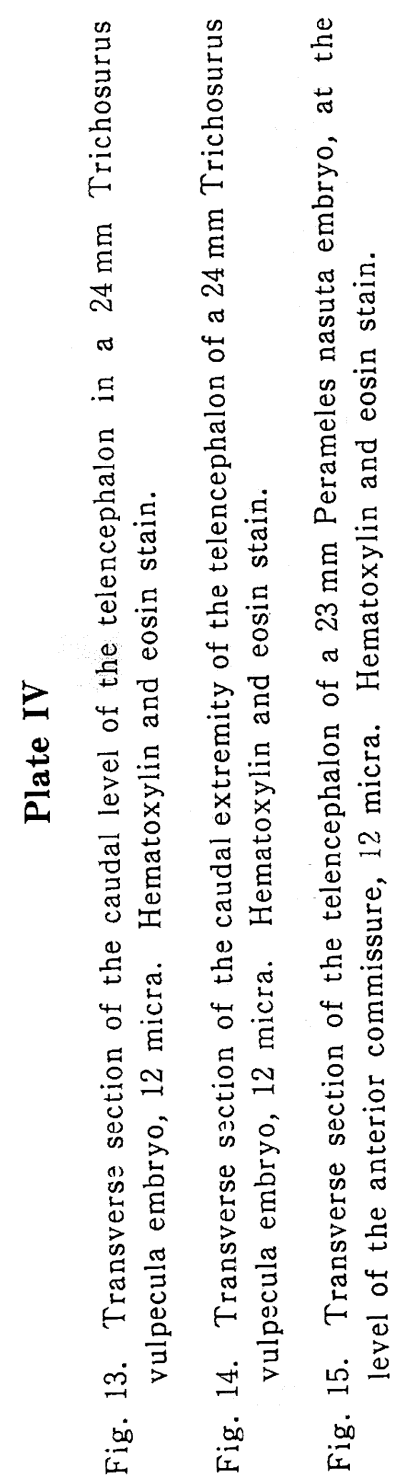



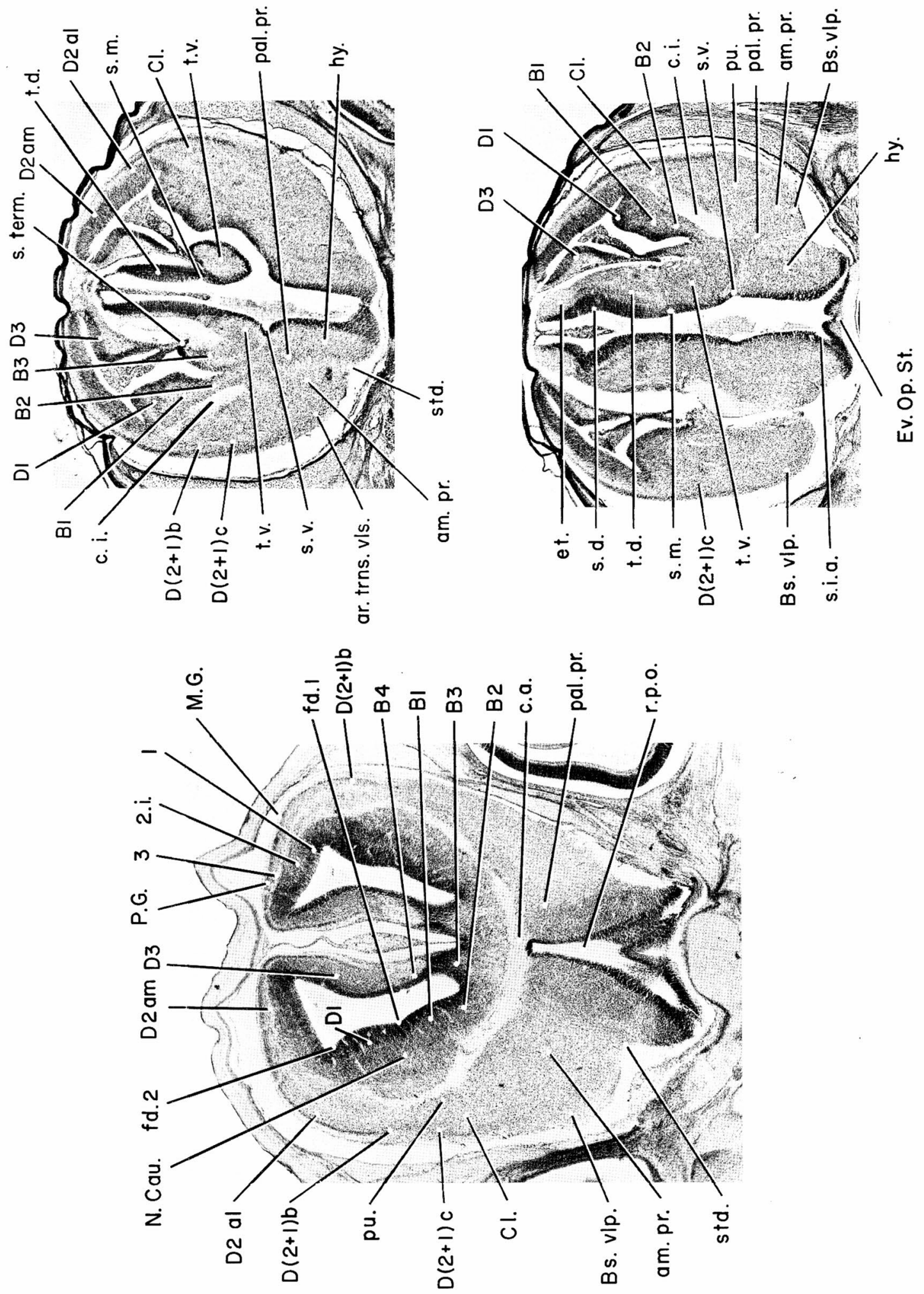


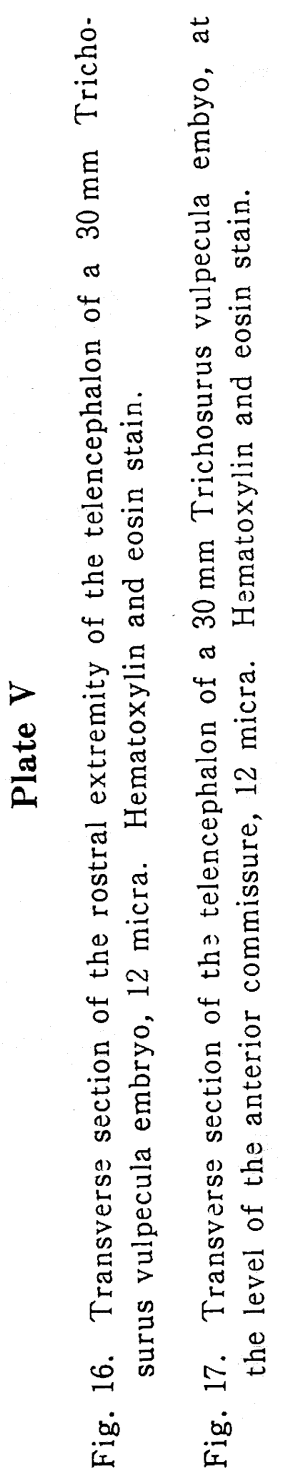


Plate V
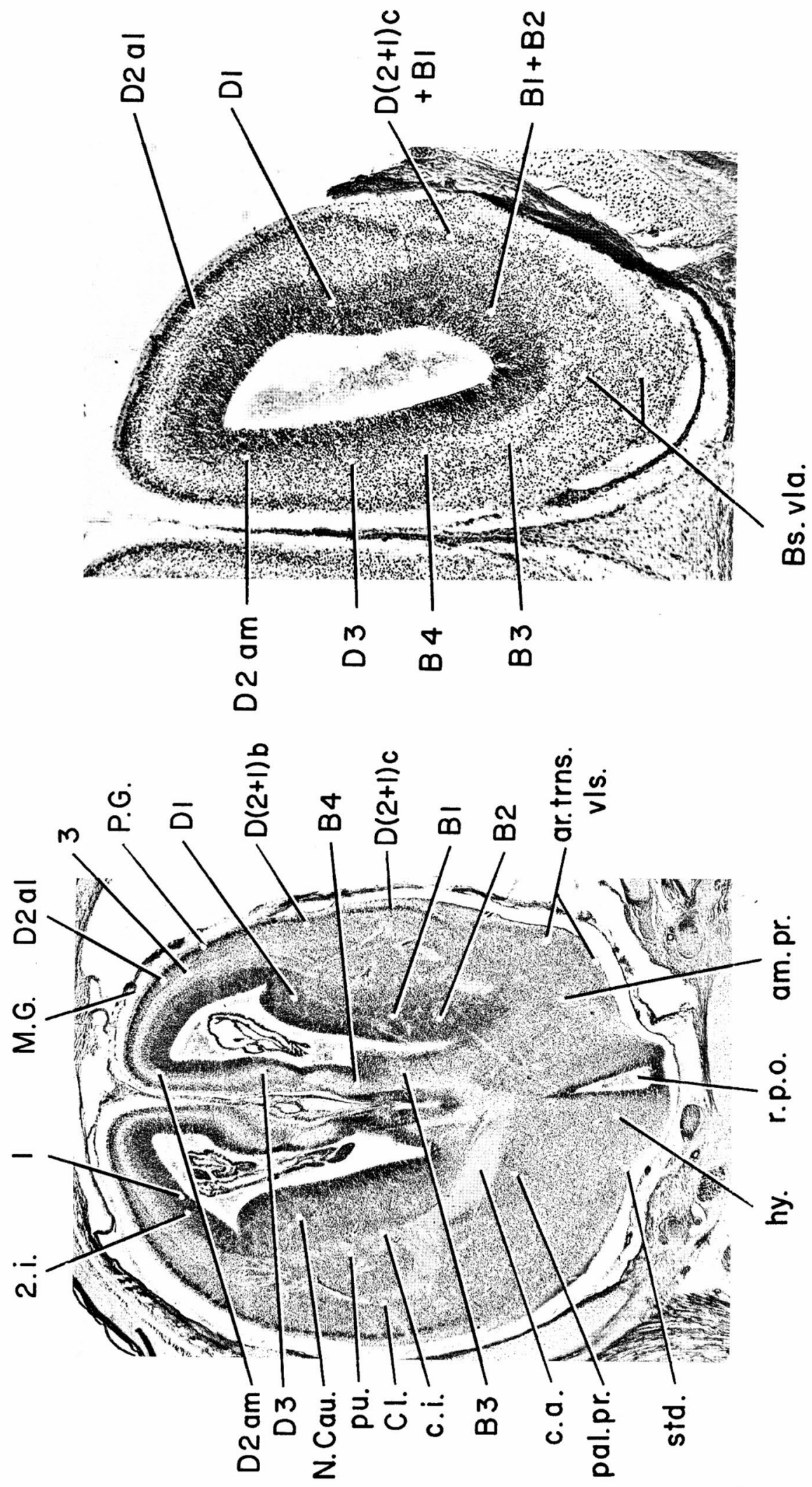


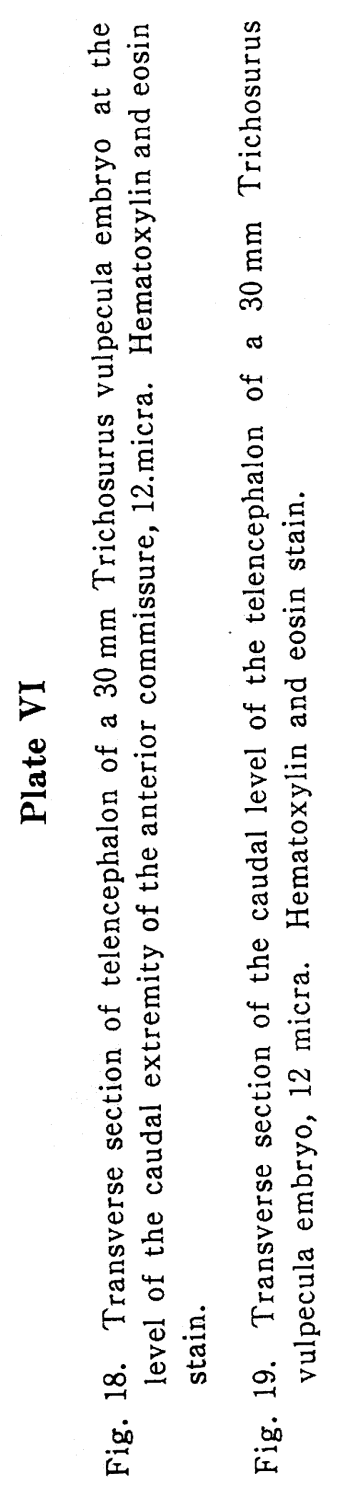



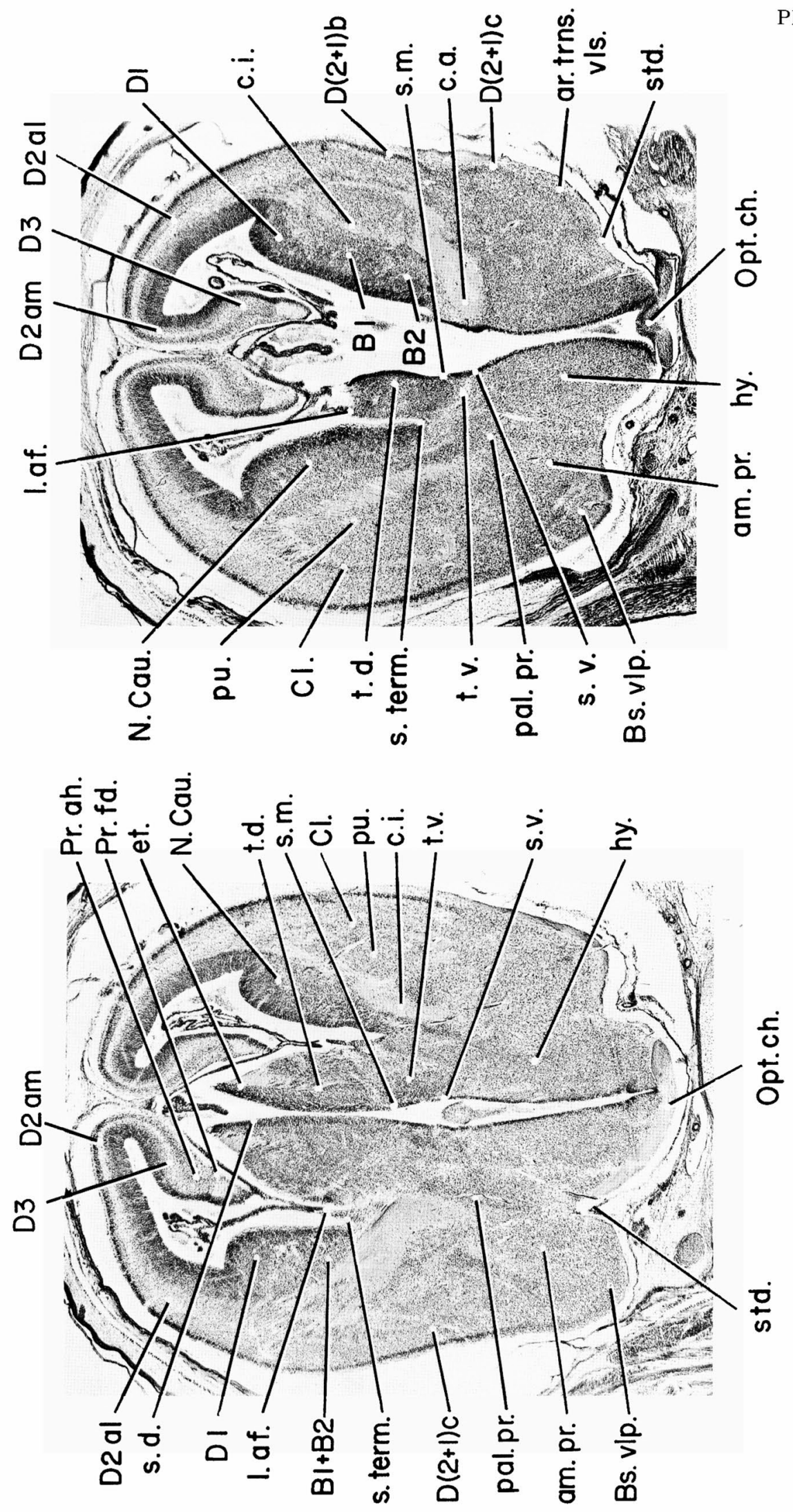


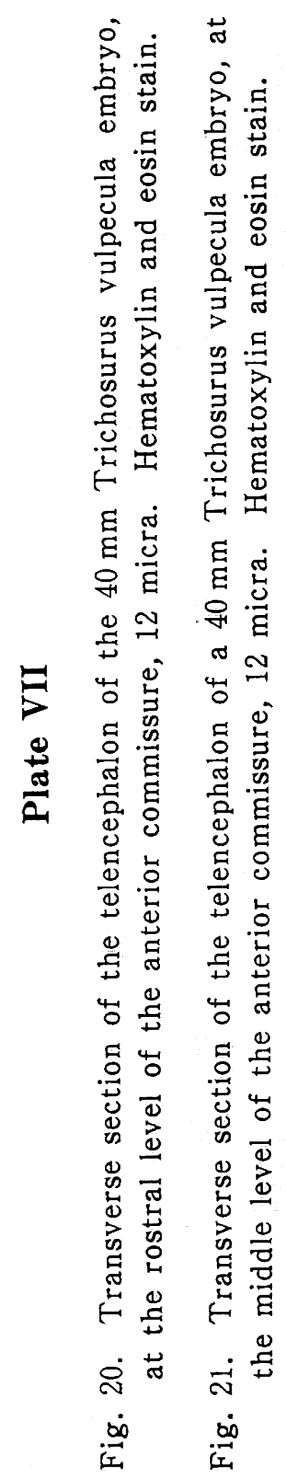


Plate VII
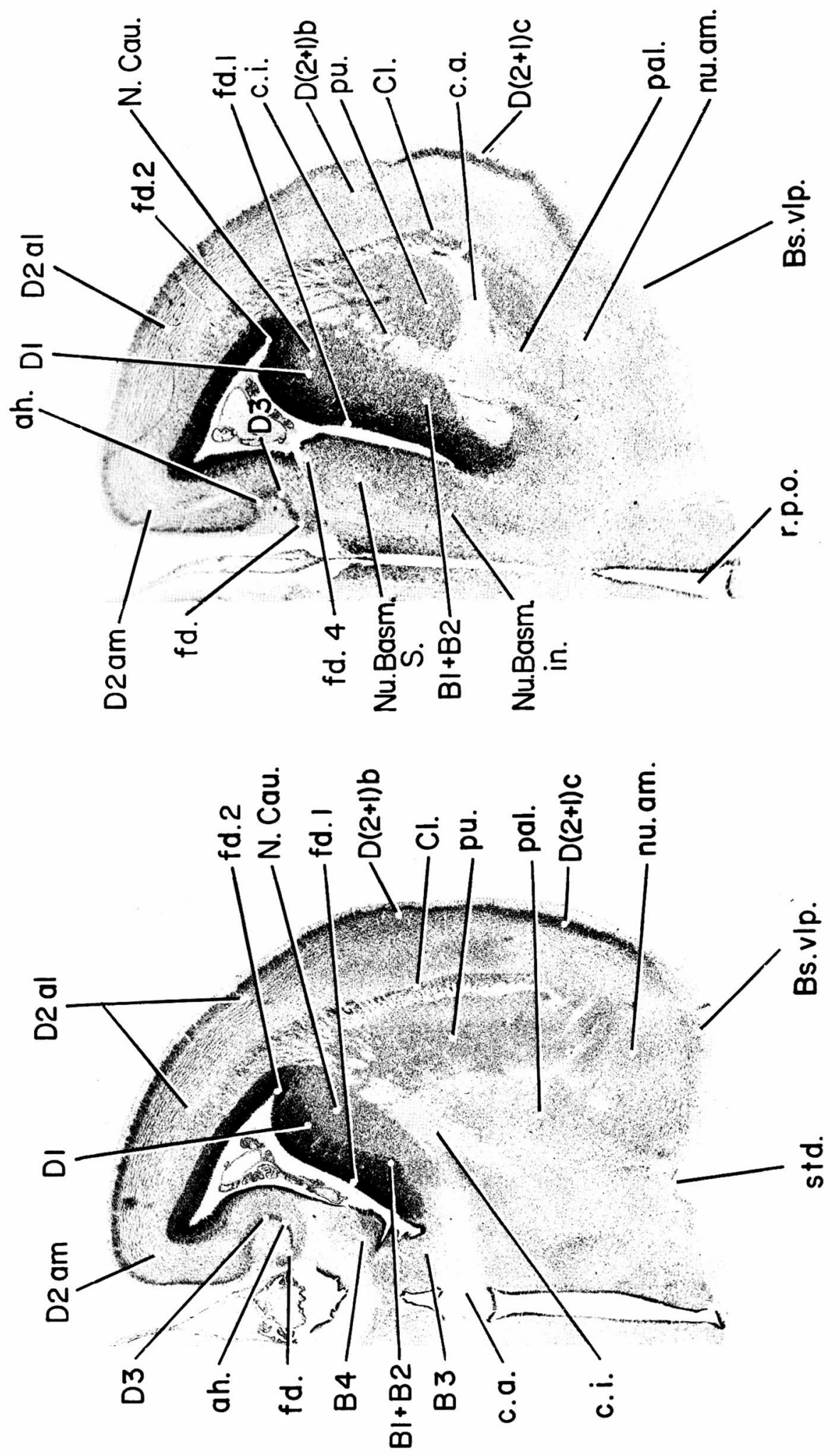


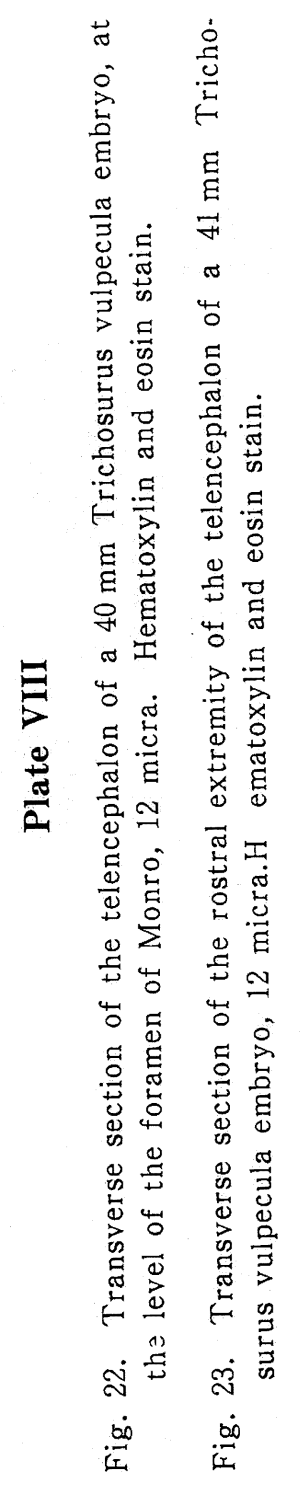



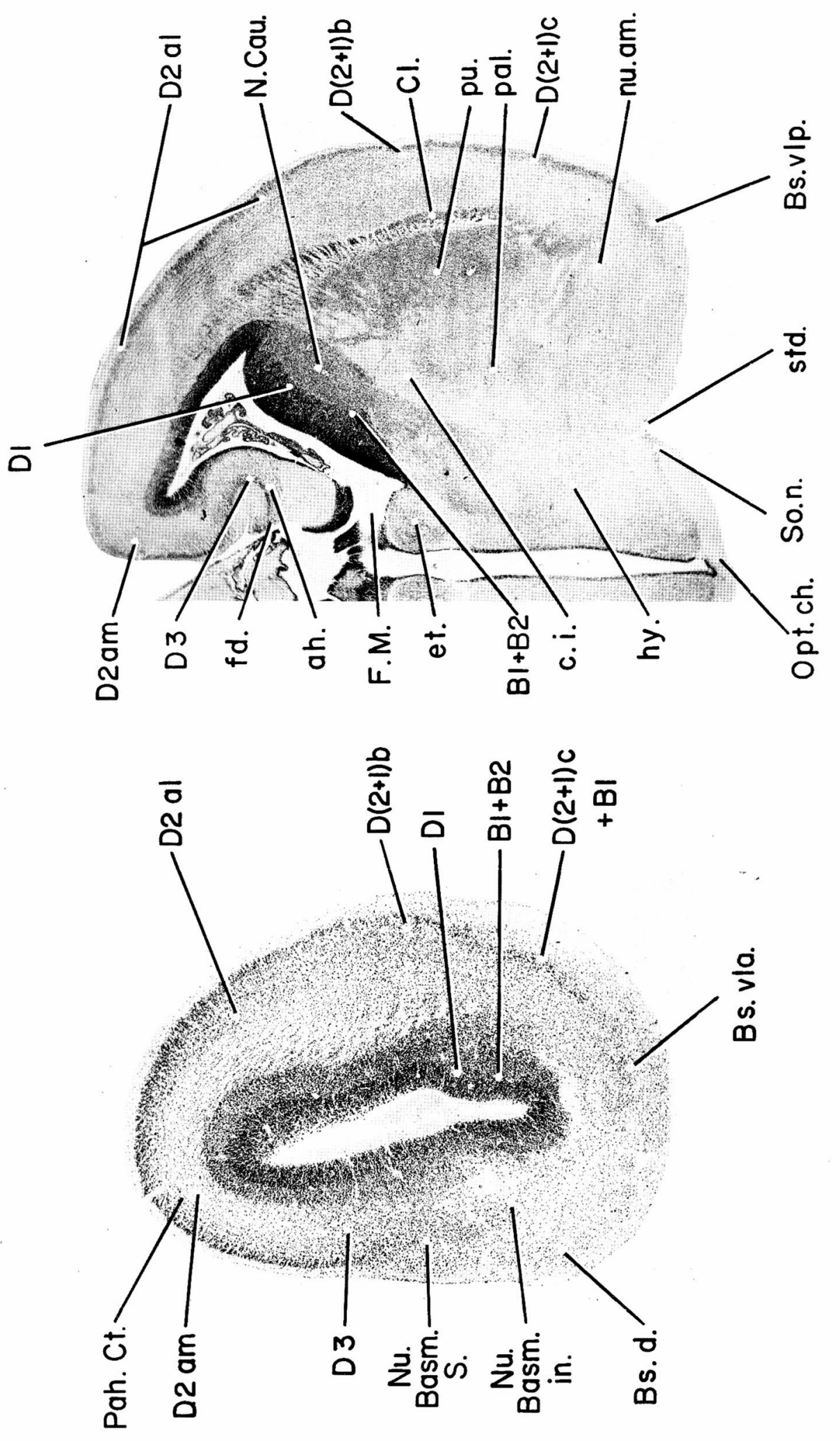


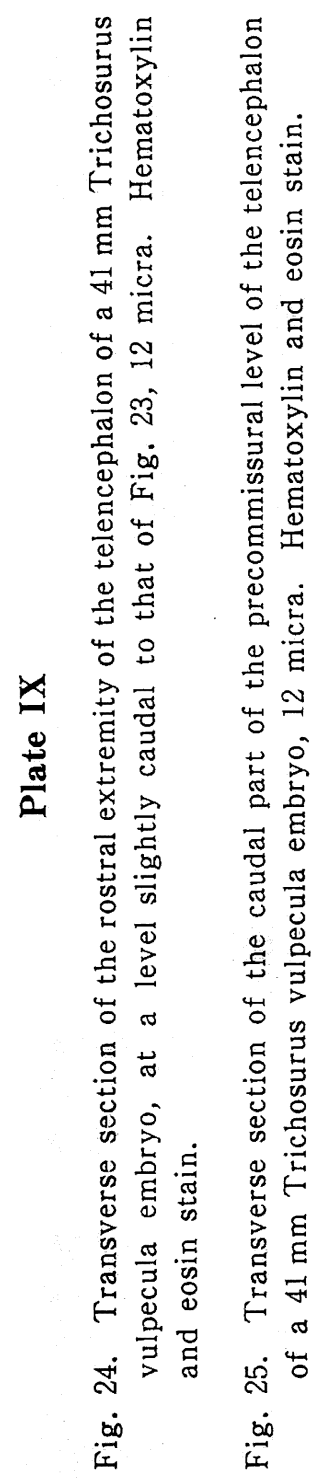


Plate IX

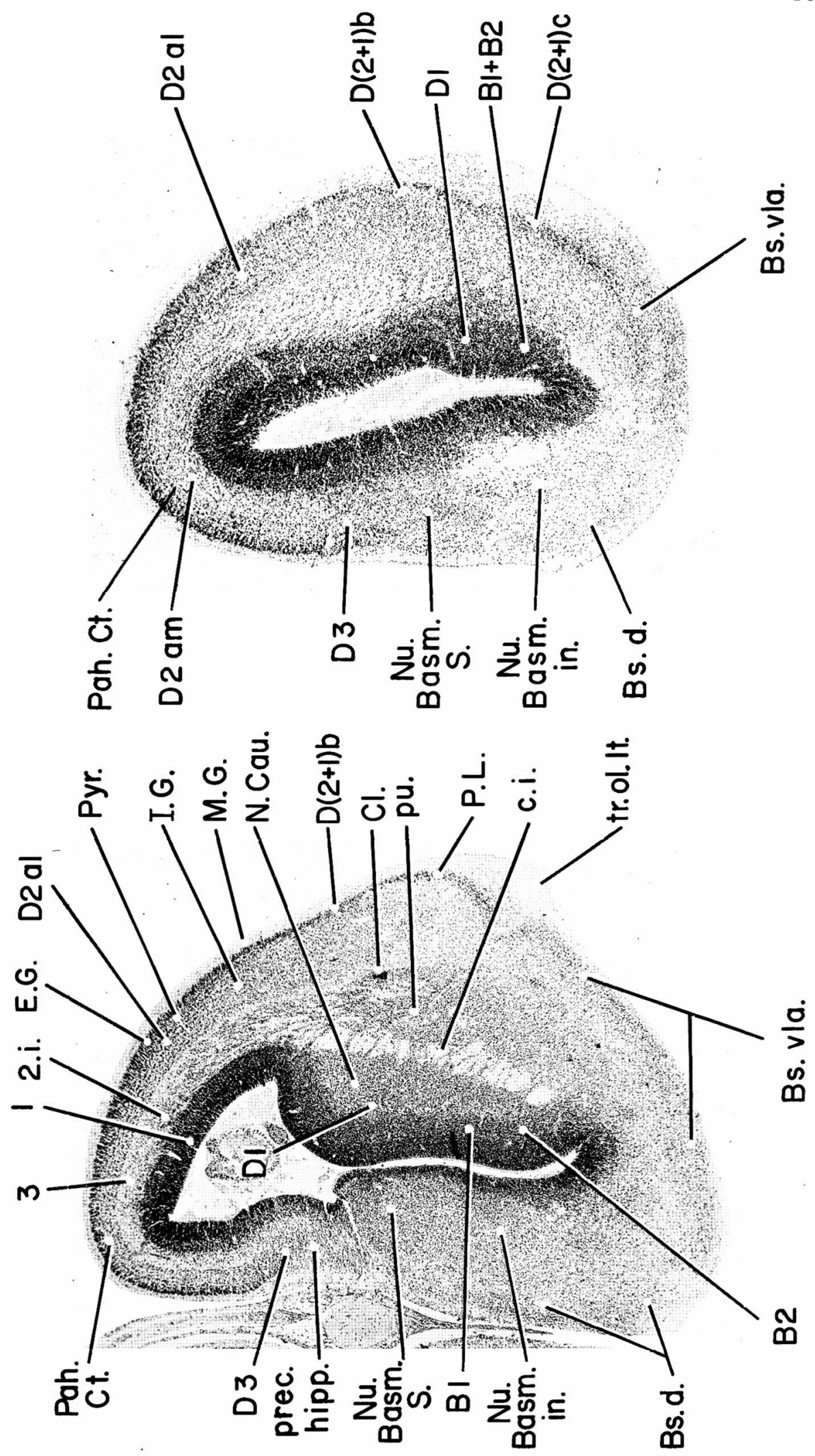




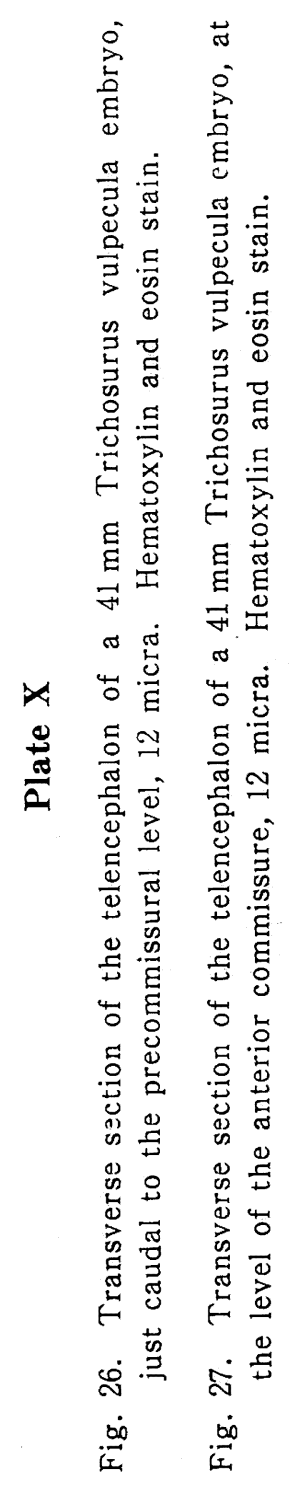



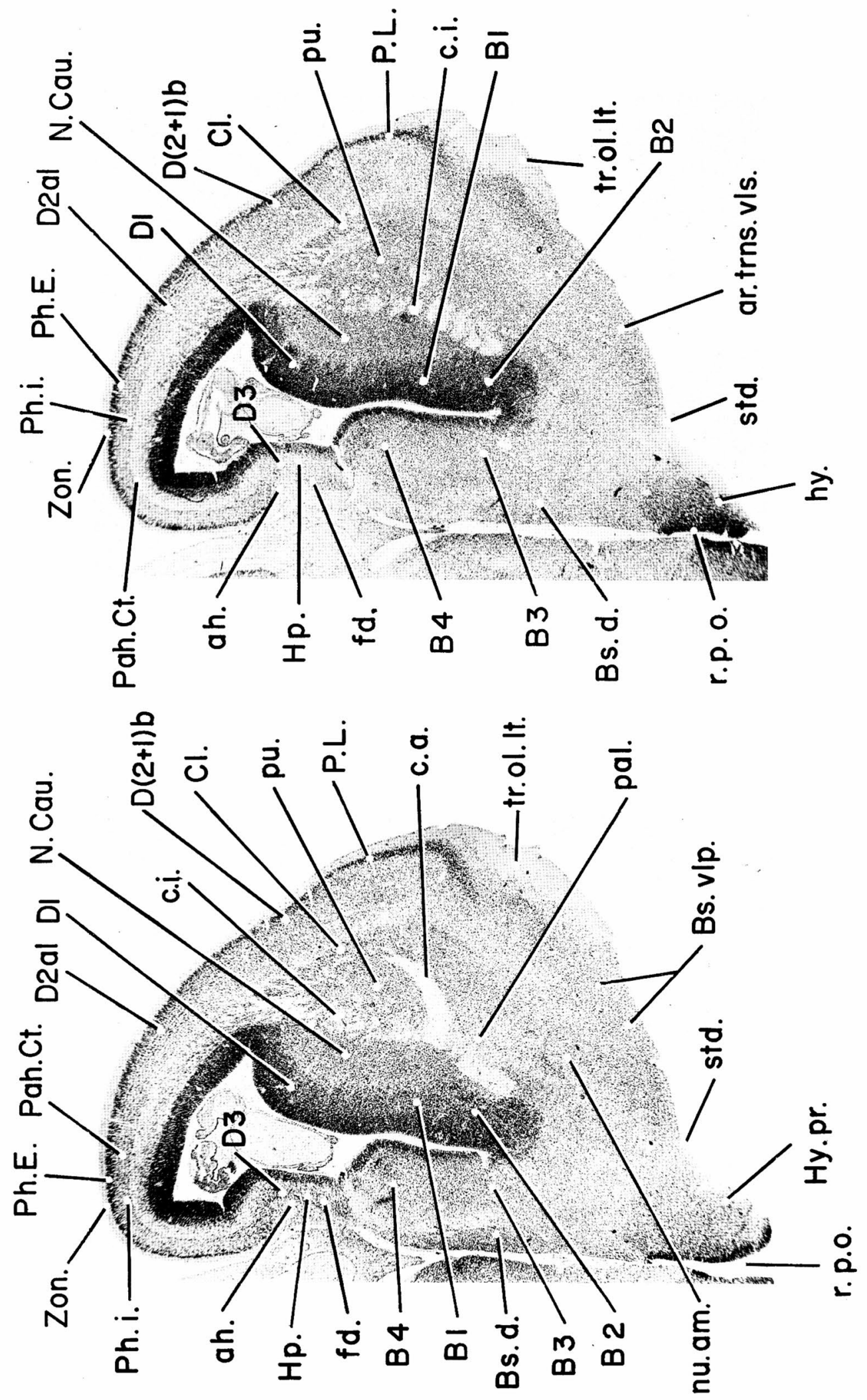


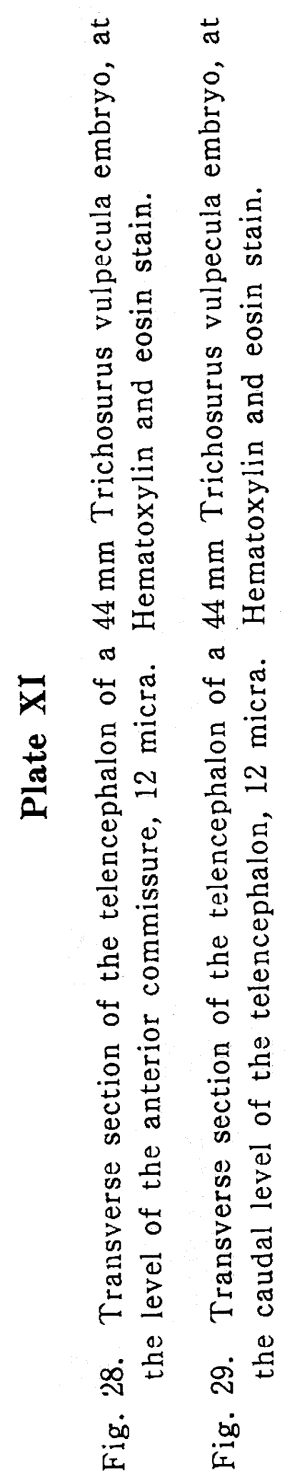



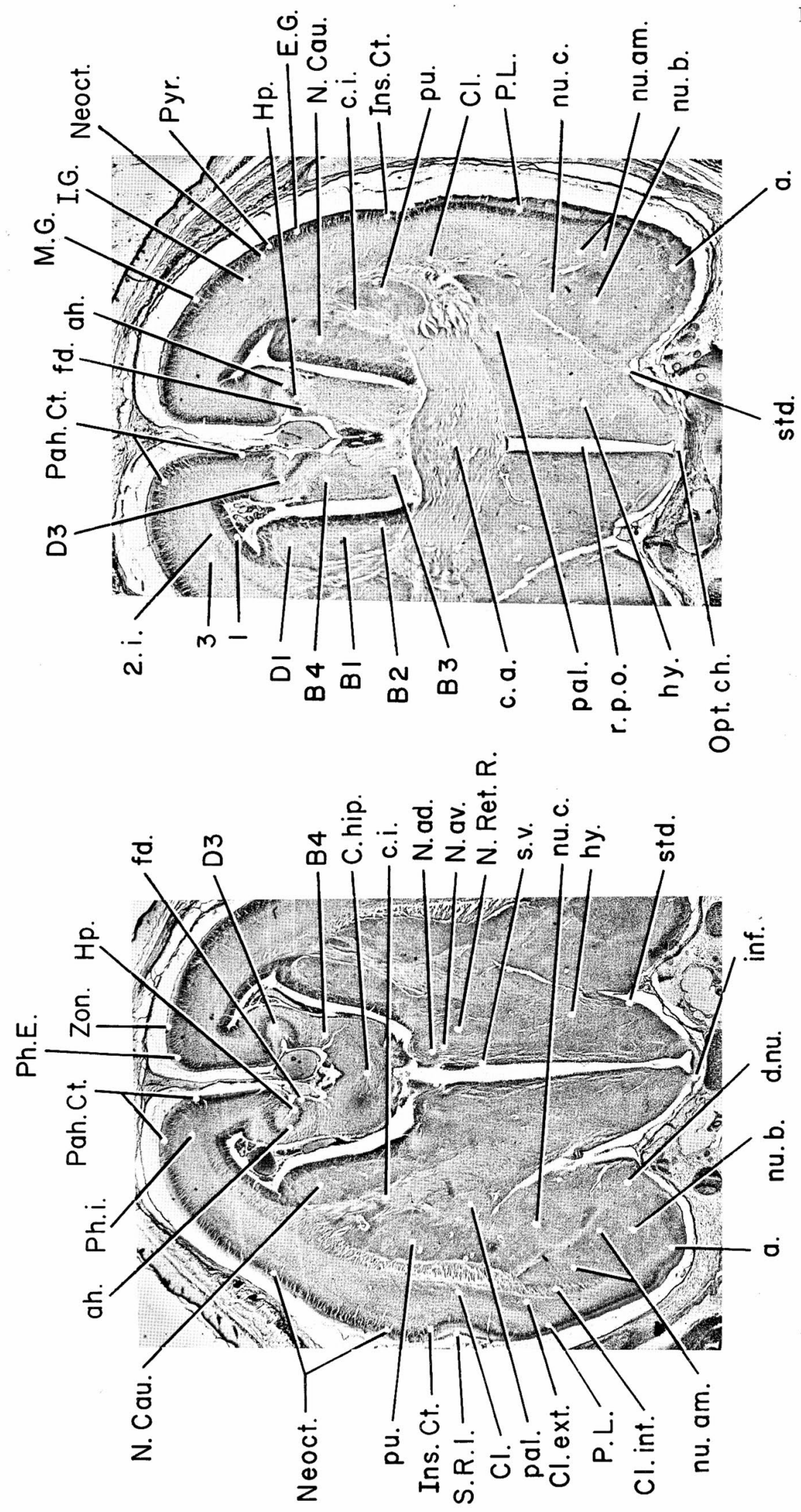


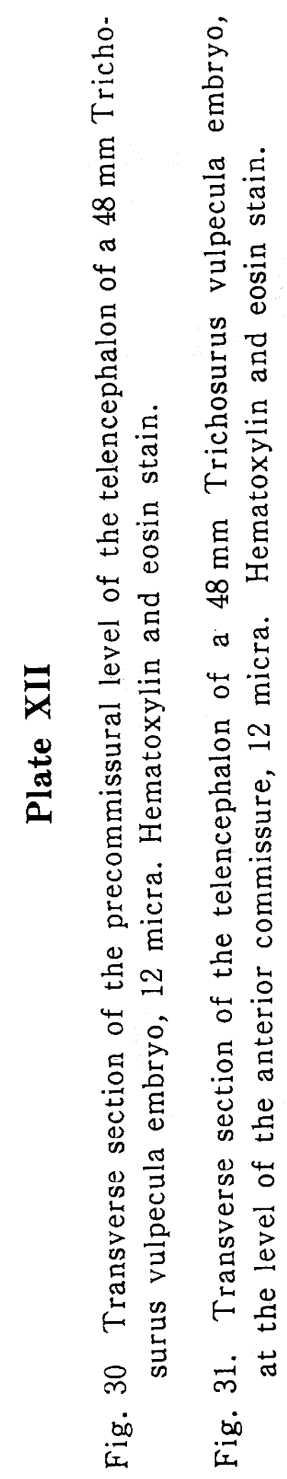



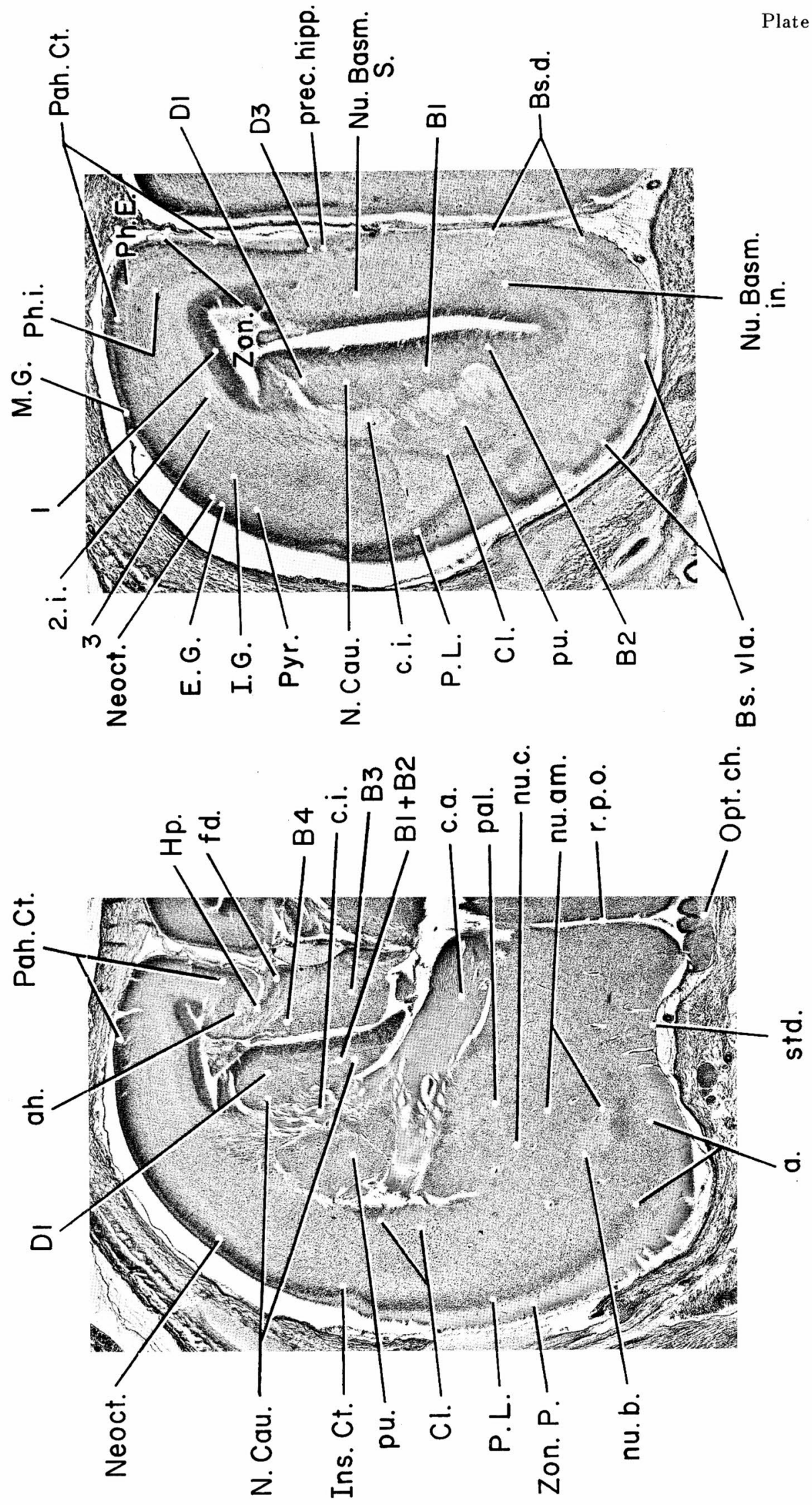


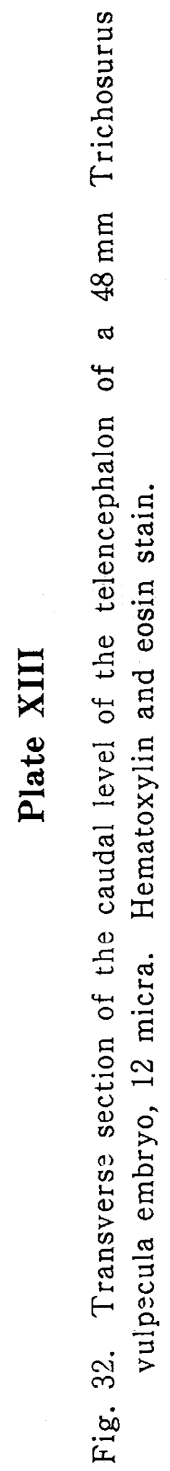




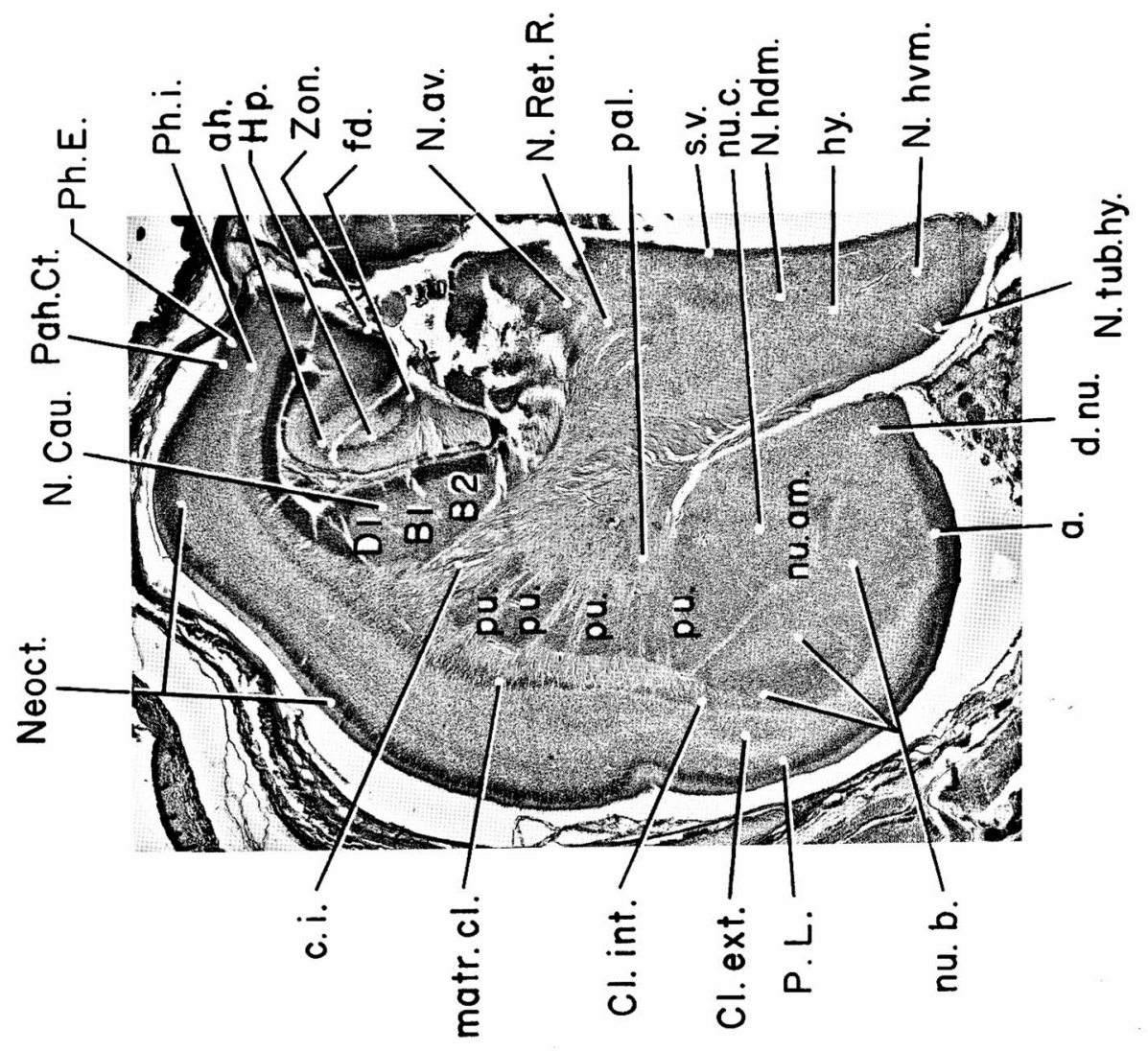

